\title{
Unsteady Heat Conduction Study During Underground Coal Gasiflcation For Constructing an In-situ Pyrolysis Project.
}

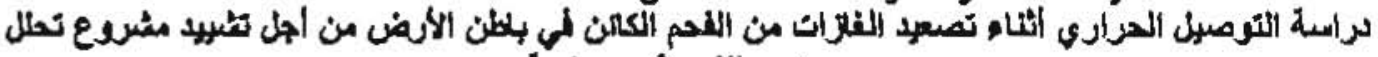

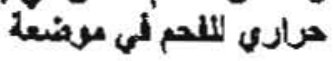

Prof.Dr. Aly M. El-Zahaby (Mechanical power Eng. Depi. Tanta Unlversity),

Prof.Dr. M. Khalil Bassiouny (Mechanlcal power Eng.Dept. Menoufla Unlversity).

Dr.Ayman Bakry, (Mechanlcal power Eng. Dept. Tanta University)

And Eng. All Ahmed Ghall ( Delta Sugar Company Kafer El sheikh)

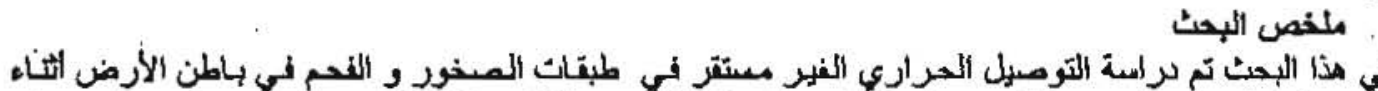

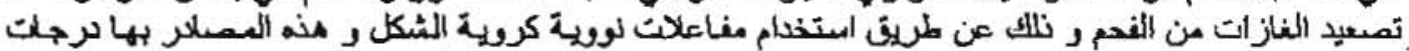

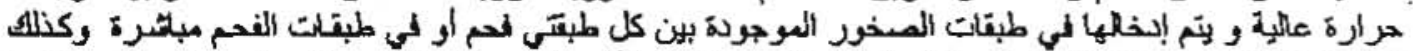

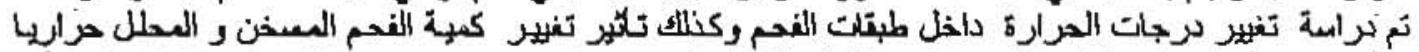

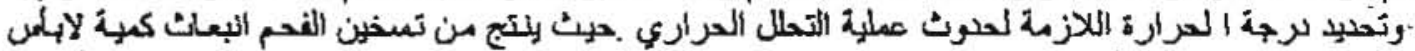

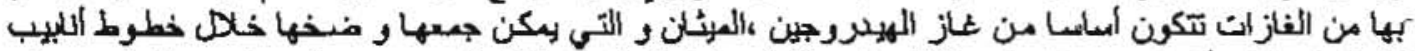

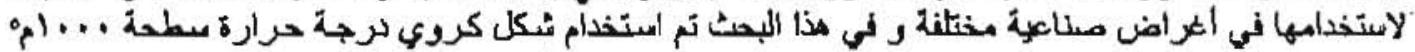

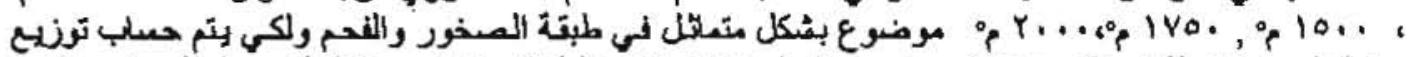

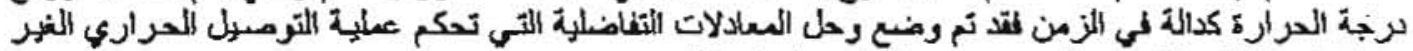

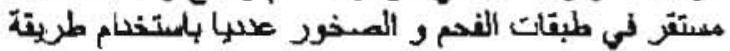
"The discretization equation (control-volume formulation)"

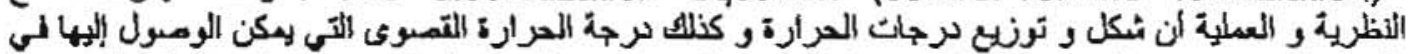

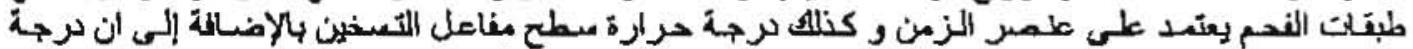

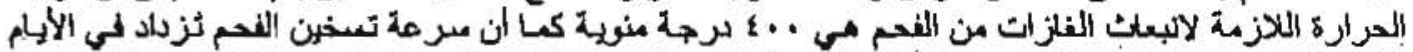

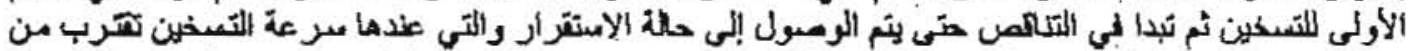

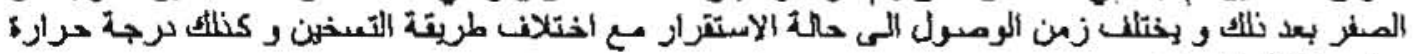
منع مغاعل التصخين.

\begin{abstract}
Underground coal gasification (UCG) is a potentlal coal utilization technology, recelving renewed interest around the world. in the last five years there has been increasing Interest in the world energy and mining Industry for the development of a new operating underground coal gasification systems to generate synthetic gas from underground coal seams. in this paper, the problem of unsteady heat conduction in the underground coal and rock layers during underground gasiflcation is considered. The heating of coal results in releasing considerable amount of gases mainly hydrogen and methane which would be collected and pumped through plpelines for the use in different industrlal appilcations. In the present analysls, a spherical type heat source having a surface temperature of $\left(1000^{\circ} \mathrm{C}, 1500^{\circ} \mathrm{C}, 1750^{\circ} \mathrm{C}\right.$ and $\left.2000^{\circ} \mathrm{C}\right)$ is used for heating the coal layer for achieving the pyrolysis process. The differential equations describing the unsteady heat conduction in both coal and rock layers are solved numerically using the discretization method (control-volume formulation). A computer program is constructed for calculating the temperature flelds and the gasified volumes of mineral coal as well as the heating velocity in the coal seams. In the experimental part, a model of underground coal layer is constructed. To validate the numerical model, an electrical spherical heat source is inserted directly into the coal layer for heating. The temperature distribution in coal layer is measured in different locations using the
\end{abstract}


and Eng. Ali Ahmed Ghali

thermocouples. The results show that the temperature profiles and the maximum attainable temperature in the coal seams depend on the time and the surface temperature of the heating reactor. Furthermore, the gasified volume of coal increases with the increase of both the surface temperature of the heating source and the running time. It is found also that the heating velocity in the underground coal lies between the mean value $\left(2\right.$ to $10^{-3} \mathrm{~K} / \mathrm{min}$.) and increases with the time to reach a maximum value, after this it decreases to approach zero at the steady-state conditions. This study indicates that geometry, position, surface temperature and distribution of heating sources are very important parameters which should be carefully chosen for realizing an efficient pyrolysis of underground coal and avoiding thereby the combustion of a part of the coal seams. The analysis indicated that the best temperature is between $\left(700-800^{\circ} \mathrm{C}\right)$ at which the high efficiency of pyrolysis process, the analysis might be useful in constructing an in-situ pyrolysis project for utilizing the underground coal seams.

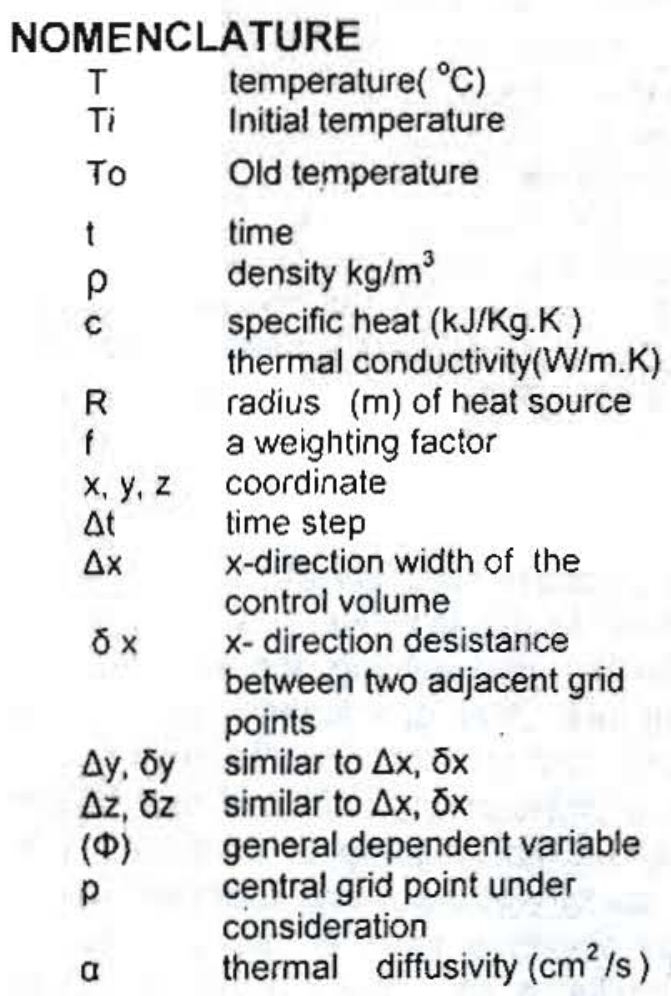

\subsection{NTRODUCTION}

The term "coal" used to describe a variety of fossilized plant materials, but no two coals are exactly alike. Heating value, ash melting temperature, sulfur and other impurities, mechanical strength, and many other chemical and physical properties must be considered when matching specific coal to a particular application. Gaseous fuel are among the most sought - after raw materials and energy sources in the energy economy. Although the gasification of coal was practiced as long ago as the 19th century and was developed to an advanced stage of technology in the first half of the present century. especially in Europe, nowadays it is of importance only in a few countries with special economic conditions. Three main routes can be followed for producing gas from coal on a large industrial scale. Processes involving pyrolysis are the most important, both quantitatively and economically. During pyrolysis, the coal volatile constituents are cracked to give gaseous and liquid products, which can be separated and treated to provide marketable byproducts.[1]. In the primary-metal industries coal is used to produce coke for blast furnaces and foundries and for power generation in steel and rolling mills. Significant amounts of coal are also used for power generation in the food, paper, chemical and ceramic industries. Pyrolysis typically occurs under pressure and operating temperature above $430^{\circ} \mathrm{C}$ (EX-situ Remediation technology)[6]. Pyrolysis processes can be divided into two groups: low temperature and high temperature. The product of pyrolysis processes 
can be controlled by temperature and the rate of material heating. At high temperature, the major product is gas, while at the low temperature The major product is tar or heavy oil. High heating rates minimize char formation by breaking down higher molecular species into gases products. The Laminar Energy Research Center [LERC] conducted an underground coal gasification experiment in sub bituminous coal seam, the results estimate the position and the average temperature between $\left(477-727^{\circ} \mathrm{C}\right)$ to be obtained with respect to forward gasification. The LFC (liquid from coal)[3] technology is built around a mild pyrolysis or mild gasification process that involves heating the coal under carefully controlled conditions. The Commonwealth Scientific and Industrial Research Organization of (CSIRO) energy technology and the university of NSW( New South Wales, Sydney, Australia )[1], have undertaken to develop a numerical model of the UCG processes aimed for simulating the physico-chemical process together with cavity growth and, ultimately, strata collapse. Serio [6] has been a principal investigator on experimental and/or modeling studies on pyrolysis, gasification, liquifaction, and combustion of coal which include characterization and development of advanced fuel formulation and pyrolysis of material. $\mathrm{He}$ developed advanced fuel research widely used FG-DVC model (Functional-Group, Depolymerization, Vaporization, Cross-linking Model) [6]. The system allows the sample to be heated on a pre-programmed temperature profíle, at rates $3-100^{\circ} \mathrm{C}$ $\mathrm{min}^{-1}$, up to a temperature between $20^{\circ} \mathrm{C}$ and $1100^{\circ} \mathrm{C}$. Isothermal steps with a specified hold time are also possible. The system continuously monitors the time-dependent evolution of the gases (including specific identification of the individual species such as, $\mathrm{CH}_{4}, \mathrm{C}_{2} \mathrm{H}_{6}, \mathrm{C}_{2} \mathrm{H}_{4}$, $\mathrm{C}_{2} \mathrm{H}_{2}, \mathrm{C}_{3} \mathrm{H}_{8}$, benzene, etc...) [7]. The performance of corresponding in-situ pyrolysis project of coal, biomass and waste materials is depending decisively on how the heating of coal and the surrounding rocks can be accomplished through applying suitable heating sources. The suggested heating sources may be point, flat plate, or spherical shaped nuclear bodies of high surface temperatures. They can be placed either in the underground rock layers or directly in coal seams, this study is used for determining the temperature distribution in rock and coal layers to calculate the amount of heated volume of coal which be able to gasify and the heating velocity in coal layer.

\section{MODEL DESCRIBTION}

Coal is found as a layers between other layers of ground mostly different types of rocks with different thickness, thermal conductivities, densities, specific heats, and different thermal diffusivities, some of physical properties of solids at corresponding temperature such as density, specific heat at constant pressure, thermal conductivity, and thermal diffusivity are given in table (1). The problem of unsteady-state heat conduction in the coal and rock seams is considered. In this model, the heat source is taken as a spherical shaped reactor of radius " $R$ " $(m)$ and constant temperature " $\mathrm{T}_{0}$ " $(\mathrm{K})$ which inserted at different positions. Three cases are studied, in the $1^{\text {st }}$ case the heat source is inserted directly in the coal seams of thickness $D_{C}$ with Initial Temperature $\left(T_{1}\right)$ not surrounded with rock), Fig.(1.a). The $2^{\text {nd }}$ case 
and Eng. Ali Ahmed Ghali

the heat source is inserted directly. in the coal seams between two parallels rock seams of thickness "Dr" $(m)$, Fig.(1.b). While for the third case the heat source is inserted into a rock layer of thickness " $D_{r} "(m)$

between two parallels coal seams of thickness " $D_{c}$ "(m), Fig.(1.c). For the problem treatment, the Cartesian coordinate $\operatorname{system}(x, y, z)$ is selected, where its position is shown Fig. 1

Table (1) Properties of solids from (Adrian Bejan, heat transfer appendix B).

\begin{tabular}{|l|c|l|l|l|l|}
\hline Types & $\begin{array}{c}\text { Temperature } \\
\mathrm{T}\left({ }^{\circ} \mathrm{C}\right)\end{array}$ & $\begin{array}{l}\text { Density } \\
\rho\left(\mathrm{kg} / \mathrm{m}^{3}\right)\end{array}$ & $\begin{array}{l}\text { Specific heat } \\
\mathrm{Cp}(\mathrm{KJ}(\mathrm{kg} . \mathrm{K})\end{array}$ & $\begin{array}{l}\text { Thermal } \\
\text { conductivity } \\
\mathrm{k}(\mathrm{W} / \mathrm{m} . \mathrm{K})\end{array}$ & $\begin{array}{l}\text { Thermal } \\
\text { diffusivity } \\
\mathrm{a}\left(\mathrm{cm}^{2} / \mathrm{s}\right)\end{array}$ \\
\hline Coal & 20 & $1200-1500$ & 1.26 & 0.26 & $\begin{array}{l}0.0014- \\
0.0017\end{array}$ \\
\hline Anthracite & 900 & 1500 & & 0.2 & \\
\hline Brown coal & 900 & & & 0.1 & \\
\hline Bituminous in-situ & & 1300 & & $0.5-0.7$ & $0.003-$ \\
\hline Dust & 30 & 730 & 1.3 & 0.12 & 0.004 \\
\hline $\begin{array}{l}\text { Concrete, made } \\
\text { with gravei, dry }\end{array}$ & 20 & 220 & 0.88 & 1.28 & 0.0066 \\
\hline Cinder & 20 & & & 0.76 & \\
\hline Granite & 20 & 2750 & 0.89 & 2.9 & 0.012 \\
\hline Sandstone & 20 & $2150-2300$ & 0.71 & $1.6-2.1$ & $0.01-$ \\
\hline
\end{tabular}

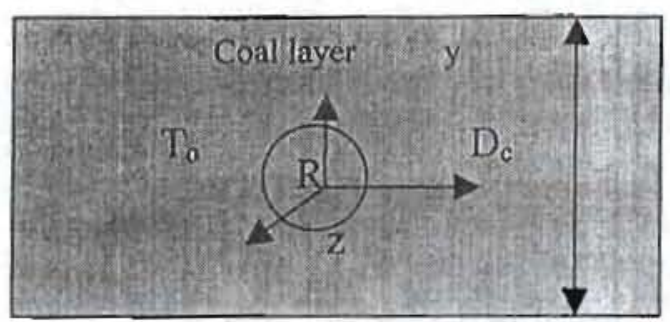

a. Case 1: HS inserted in infinite coal

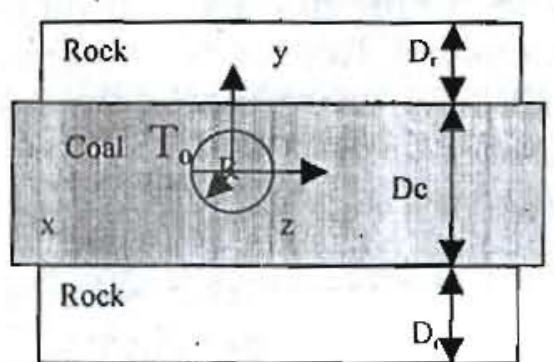

b. Case 2: HS inserted in coal layer

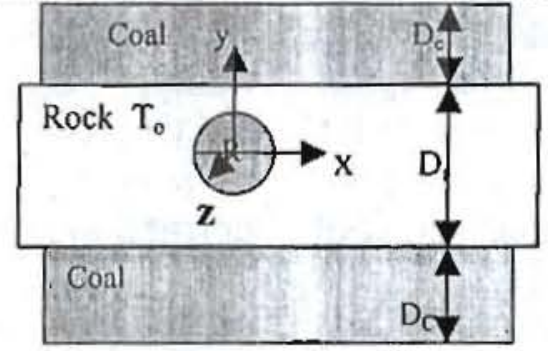

c. Case 3: HS inserted in rock layer

Fig.1 The cases of different positions of spherical type heat source (HS) with the selected Cartesian coordinate system

\section{THEORETICAL ANALYSIS}

The basic differential equation for determining the temperature fields in both rock and coal layers is obtained by coupling the energy equation and Fourier's law of heat conduction. This yields the following differential equation describing the temperature distribution for one dimension, unsteady heat conduction, where the applied heat source causes constant surface temperature at the inner boundary is described as :

$\rho c \frac{\partial T}{\partial \ell}=\frac{\partial}{\partial x} \frac{k \partial T}{\partial x}$

For constant properties ( $\rho, c, k)$, the previous differential equation is reduced to

$\frac{\partial T}{\partial t}=\alpha \frac{\partial^{2} T}{\partial x^{2}}$ 
where $(\alpha=k / \rho c)$ is the thermal diffusivity. The present model concerns with a spherical type heat source inserted according to different position of fig. 1. In this model, both the heat needed for drying the coal and the heat of chemical reaction as well as the variation of physical properties of rocks and coal with temperature will be neglected for the sake of simplicity. Under these conditions, the governing differential equations which describe the temperatures variation of the underground layers with time in the three dimension $(x, y, z)$. may be given as follows : For rock layer

$\frac{\partial T_{r}}{\partial t}=\alpha_{r}\left(\frac{\partial^{2} T_{r}}{\partial x^{2}}+\frac{\partial^{2} T_{r}}{\partial y^{2}}+\frac{\partial^{2} T_{r}}{\partial z^{2}}\right)$

For coal layer

$\frac{\partial T_{i}}{\partial t}=\alpha_{c}\left(\frac{\partial^{2} T_{t}}{\partial x^{2}}+\frac{\partial^{2} T_{t}}{\partial y^{2}}+\frac{\partial^{2} T_{t}}{\partial z^{2}}\right)$.

The governing differential equations (2\&3) are solved by using the discretizaton method. The initial and boundary conditions associated with equation (2), (3) are:

$\mathrm{T}=\mathrm{T}_{1}$ at $\mathrm{t}=0$,

$R \leq \sqrt{\left(x^{2}+y^{2}+z^{2}\right)} \leq \infty$

$\mathrm{T}=\mathrm{T}$, at $\mathrm{t}>0, \quad \mathrm{x}, \mathrm{y}, \mathrm{z} \rightarrow \infty$

$T=T_{0}$ at $t \geq 0, x^{2}+y^{2}+z^{2}=R^{2}$

$T_{t}=T_{c}$ at $t \geq 0, y=D_{r} / 2, \quad y=-D_{1} / 2$

Equations (2\&3) are linear partial differential equations of second order of parabolic type. Because these differential equations with initial and boundary conditions are relatively. complex, they are solved numerically using the finite difference method (control-volume formulation). In case of heterogeneous (an isotropic) layers, equations (2) and (3) may be stated as:

$\rho c \frac{\partial T}{\partial t}=\frac{d}{d x}\left(\frac{k \partial T}{\partial x}\right)+\frac{\partial}{\partial y}\left(\frac{k \partial T}{\partial y}\right)+\frac{\partial}{\partial z}\left(\frac{k \partial T}{\partial z}\right)$

The discretization equation which describes the previously mentioned differential equations can be written as follows :

$a_{p} T_{p}=a_{e} T_{e}+a_{w} T_{w}+a_{n} T_{n}+a_{s} T_{s}+$

$a_{1} T_{1}+a_{b} T_{b}$

where $T_{p}$ is the pole temperature, $T_{e}$ , $T_{w}, T_{n}, T_{s}, T_{1}, T_{b}$ are denoting east, west, north, south, top and bottom respectively, while $a$ is a constant. This discretization equation is derived by integrating the differential equations over the control volume shown in Fig. 2 and over the time interval from time " $t$ " to time $(t+\Delta t)$, as follows:

$\rho c \int_{1}^{1+\infty t} \int_{0}^{1} \int_{1}^{1} \int_{b}^{T}\left(\frac{\partial T}{\partial t}\right) d x d y d z d t=$

$\int_{1}^{n} \int_{x}^{\infty} \int_{1}^{n} \int_{n}^{T}\left[\frac{\partial}{\partial x}\left(\frac{k_{x} \partial t}{\partial x}\right) \frac{\partial}{\partial y}\left(\frac{k_{y} \partial t}{\partial y}\right) \frac{\partial}{\partial z}\left(\frac{k_{y} \partial t}{\partial z}\right) d x d y d z d t\right]$

where the order of integration is chosen according to the nature of the term. For representation of the term $(\partial \mathrm{T} / \partial \mathrm{t})$ we shall assume that the grid-point value of (T) prevails throughout the control volume then. the integration of left hand side of equation (6) yields:

$$
\begin{aligned}
& \rho c \int_{n}^{\prime \prime} \int_{i}^{n} \int_{b}^{t} \int_{1}^{t+\Delta \prime} \frac{\partial T}{\partial t} d t d z d y d x= \\
& \rho c \Delta x \Delta y \Delta z\left(T_{p 1}-T_{p o t}\right)
\end{aligned}
$$

Similarly, the integration of the right hand side of equation (6) with respect to $x, y$ and $z$ results in $\rho c \Delta x \Delta y \Delta z\left(T_{p 1}-T_{p o}\right)=$

$\int_{1}^{\prime \prime \Delta}\left(\frac{k_{c}}{d x_{n}}\left(T_{c}-T_{n}\right) \Delta y \Delta=-\frac{k_{n}}{d x_{n}}\left(T_{p}-T_{n}\right) \Delta y \Delta z+\right.$

$\frac{k_{n}}{d y^{\prime},}\left(T_{n}-T_{p}\right) \Delta x \Delta=-\frac{k}{d j^{\prime}}\left(\eta_{n}-T_{,}\right) \Delta x \Delta=+$

$\frac{k_{n}}{d z_{1}}\left(T_{1}-T_{n}\right) \Delta x \Delta y-\frac{k_{A}}{d z_{n}}\left(T_{n}-T_{1}\right) \Delta x \Delta y j d t$

At this point, we need a concept about how $T_{\rho}, T_{e}, T_{w,}, T_{n}, T_{s}, T_{1}$ and $T_{b}$ vary with time from time " $t$ " to a new time $\langle t+\Delta t\rangle$. Many assumptions are available in the literatures. One of 


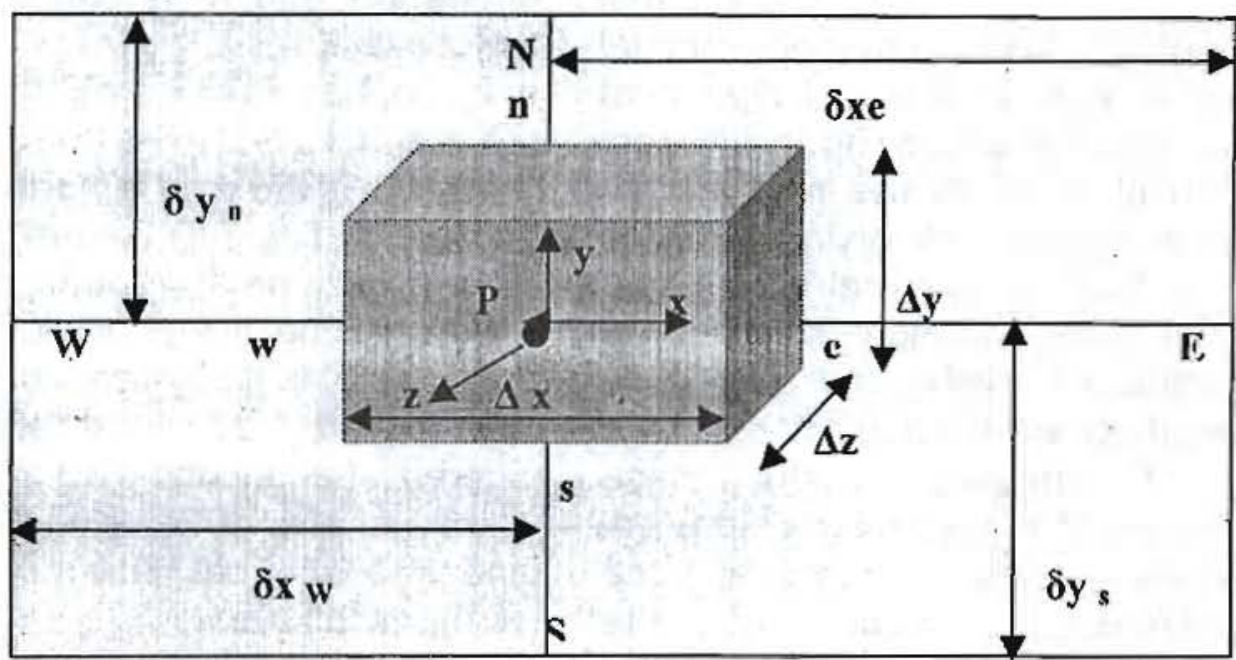

Fig.2 Schematic diagram for the discretization method illustrating nomenclature used in numerical analysis

them can be generalized by the following proposed equations:

$$
\int_{1}^{1+\Delta t} T_{p} d t=\left[f T_{p 1}+(1-f) T_{p o}\right] \Delta t
$$

(9) For the stability of equation (13), the

Where $f$ is a weighting factor. It has value between 0 and 1 .

For fully implicit schemes where $(f=$ 1), assume that $T_{e}, T_{w}, T_{n}, T_{s}, T_{1}$ vary with time from time " $\mathrm{t}$ " to time $(\mathrm{t}+\Delta \mathrm{t})$ and the increments of space coordinate are chosen such that: $\Delta \mathrm{x}=$ $\Delta y=\Delta z=\Delta L$, by substitution of equ.(9) into equ.(8) then, we have $T_{p 1}\left[\frac{\rho c \Delta L^{3}}{\Delta}+6 k \Delta L\right]=k \Delta \downarrow\left(\begin{array}{l}T_{c 1}+T_{w 1}+ \\ T_{n 1}+T_{s 1}+ \\ T_{11}+T_{b 1}\end{array}\right)+\frac{\rho c \Delta L^{3}}{\Delta} T_{p s}$

dividing both sides by $\Delta \mathrm{L}$, using

$$
\begin{array}{r}
\alpha=\frac{k}{\rho c} \text { and let } \\
A=\left(T_{e 1}+T_{w 1}+T_{n 1}+\right. \\
\left.T_{s 1}+T_{t 1}+T_{b 1}\right)
\end{array}
$$

We reach to

$$
\begin{aligned}
& T_{p 1}\left[\frac{\Delta L^{2}}{\Delta t}+6 \alpha\right]=\left[\alpha A+\frac{\Delta L^{2}}{\Delta t} T_{p p}\right] \\
& T_{n=1}=\frac{\left[\alpha A+\frac{L^{2}}{\Delta t} T_{\infty}\right]}{\left[\frac{\Delta L^{2}}{\Delta t}+6 \alpha\right]}
\end{aligned}
$$
denominator would be positive

$$
\frac{\Delta L^{2}}{\Delta t}+6 \alpha \geq 0
$$

then $\frac{\Delta L^{2}}{\Delta t} \leq 6 \alpha \quad$ therefore, the sake of simplicity as follows:

$$
t=\frac{\Delta L^{2}}{6 \alpha}
$$

Then, the following relations hold for the rock and the coal

For the rock

$$
\Delta t)_{r}=\frac{\Delta L^{2}}{6 \alpha}
$$

For the coal

$$
\Delta t)_{c}=\frac{\Delta L^{2}}{6 \alpha}
$$

Since $\Delta L_{r}=\Delta L_{c}=\Delta L$

Then, The ratio of time increments of both The rock and the coal layers is obtained to be:

$$
\frac{\Delta t)_{r}}{\Delta t)_{c}}=\frac{\alpha_{c}}{\alpha_{r}}
$$

by substituting from equation (15) to equation (13), thus time increment can be taken for the 


$$
T_{n 1}=\frac{A+6 T_{p o}}{12}
$$

Resubstituting from equation (19) into equation (17), the following equation yields :

$$
T_{01}=\frac{1}{12}\left[\begin{array}{l}
T_{11}+T_{11}+ \\
T_{n 1}+T_{11}+ \\
T_{11}+T_{B 1}
\end{array}\right]+\frac{1}{2} T_{\infty}
$$

Often elementary textbooks on heat transfer derive the finite-difference equation via the Taylor-Series method and then demonstrate that the resulting equation is consistent with a heat over a small region surrounding a grid point. We have also see that the control-volume formulation can be regarded as a special version of the method of weighted residuals. The basic idea of the control volume formulation is easy to understand and lends itself to direct physical interpolation. The calculation domain is divided into a number of no overlapping control volumes such that there is one control volume surrounding each grid

Point. The differential equation is integrated over each control volume. Piecewise profiles expressing the variation of $(\Phi)$ between the grid points are used to evaluate the required integrals where the. $(\Phi)$ is the general dependent variable. The result is the discretization equation containing the values of $(\Phi)$ for a group of grid points. The discretization equation obtained in this manner expresses the conservation principle for $(\Phi)$ for the finite control volume. Just as the differential equation expresses it for an infinitesimal control volume, then applying the discretization equation:

$$
a_{p} T_{p}=a_{e} T_{e}+a_{w} T_{w}+a_{n} T_{n}+a_{s} T_{s}+
$$
$a_{t} T_{t}+a_{b} T_{b}$

When coal. or biomass is heated, many reactions including dehydration, cracking, isomerization, dehydorgenation, aromatization, and condensations take place. the products yields vary, depending on the particular feedstock composition, particle size, heating rate in solids as residence times, and the reactor temperature. For achieving the numerical solution of the discretization equation (contro)volume formulation). A developed "Geothermal Processing Shemat Computer Program" is used for calculating the temperature distribution, the gasified volumes of coal and the heating velocity in the coal seams, through solving the differential equations (2\&3) associated with the already mentioned initial and boundary associated with the already mentioned initial and boundary conditions: The solution is obtained using spherical heat source of radius $R$ with a surface temperature of $\left(1000^{\circ} \mathrm{C} \quad \& 1500^{\circ} \mathrm{C} \& 1750^{\circ} \mathrm{C}\right.$ and $2000^{\circ} \mathrm{C}$ ) which inserted in different positions, Fig. 1, in three different types of coal with different composition and properties, table 2.

According to heat source position, the temperature of coal layers will increase and the layers are able to gasify when their temperature reaches above (600K). 
and Eng. Ali Ahmed Ghali

Table 2: different types of coal

\begin{tabular}{|c|l|l|l|}
\hline Coal type & $\begin{array}{l}\text { type }(A) \\
\text { Anthra- } \\
\text { cite }\end{array}$ & $\begin{array}{l}\text { type }(\mathrm{B}) \\
\text { Bitumin- } \\
\text { ous }\end{array}$ & $\begin{array}{l}\text { Type }(\mathrm{C}) \\
\text { Sub- } \\
\text { bituminous }\end{array}$ \\
\hline $\mathrm{O}$ & 5 & 3.5 & 29.5 \\
\hline $\mathrm{C}$ & 80 & 60.5 & 52.5 \\
\hline $\mathrm{S}$ & 0.7 & 2 & 1 \\
\hline $\mathrm{H}$ & 2.9 & 3.6 & 6.29 \\
\hline others & 10.5 & 9 & 9.8 \\
\hline $\begin{array}{c}\text { Thermal } \\
\text { conductivity } \\
\text { (W/m.K). }\end{array}$ & 0.26 & 0.35 & 0.5 \\
\hline $\begin{array}{c}\text { Specific heat } \\
\text { (KJ/kg.). }\end{array}$ & 1.2 & 1.26 & 1.3 \\
\hline
\end{tabular}

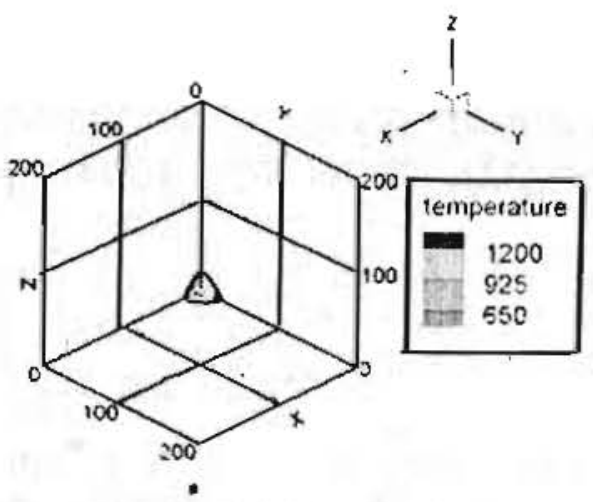

a. One day heated volume

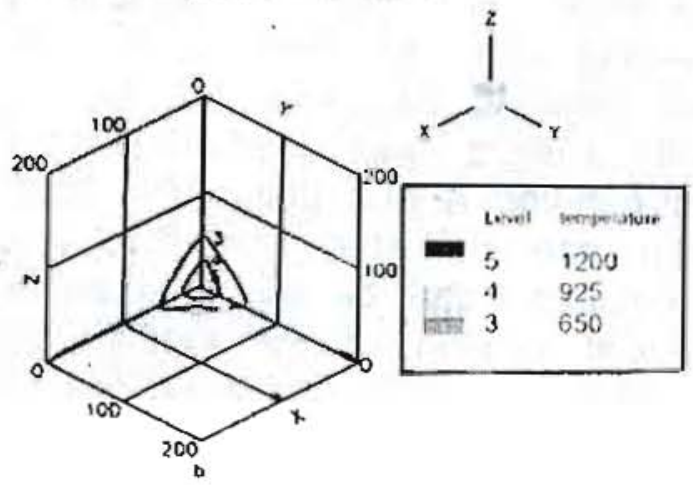

b. One week heated volume

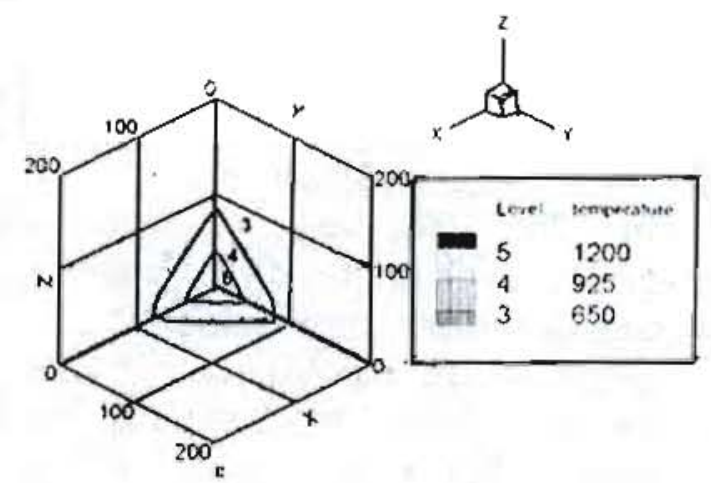

c. One month heated volume

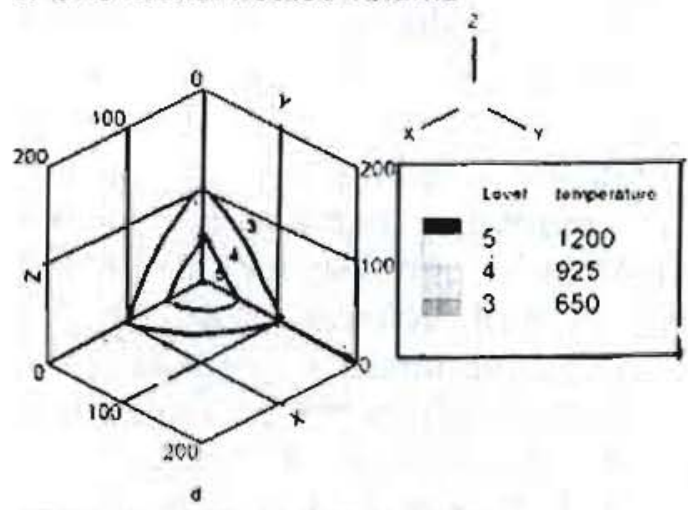

d. Two months heated volume

Fig. 3 The heated volume and temperature contours variation with time for coal type $A$ at heat source of $1000^{\circ} \mathrm{C}$ surface temperature 
Mansoura Engineering Joumal, (MEJ), Vol. 33, No. 3, September 2008.

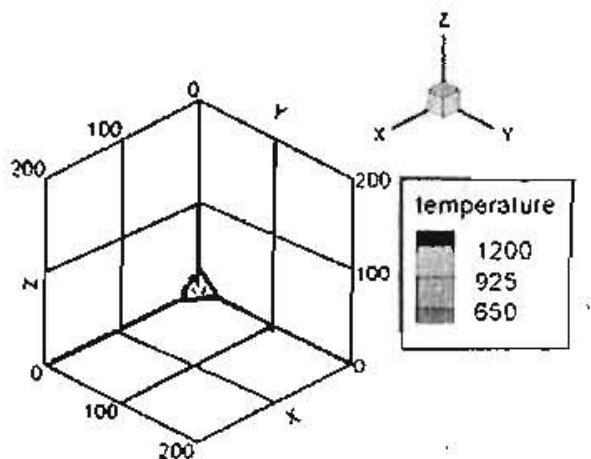

a. One day heated volume

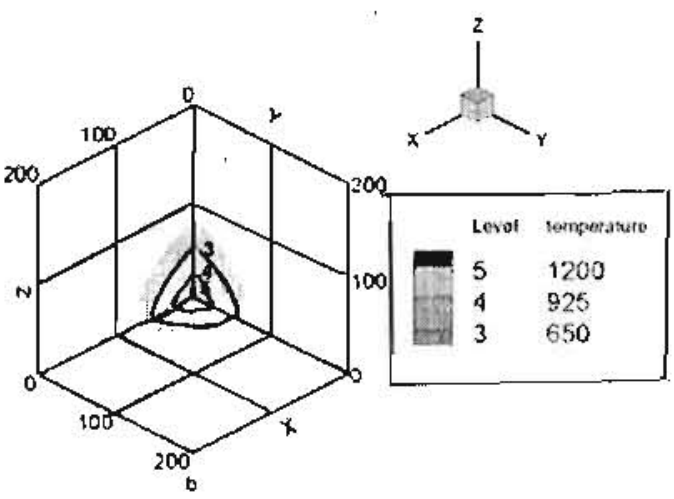

b. One week heated volume

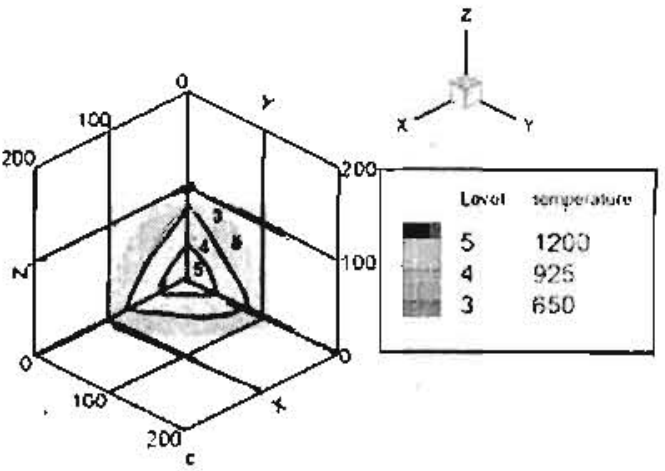

c. One month heated volume

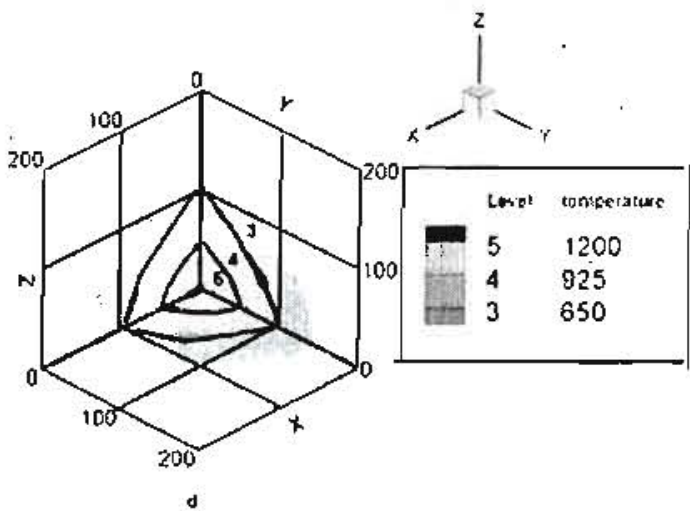

d. Two months heated volume

Fig.4 The heated volume and temperature contours variation with time for coal type $B$ at heat source $1000^{\circ} \mathrm{C}$

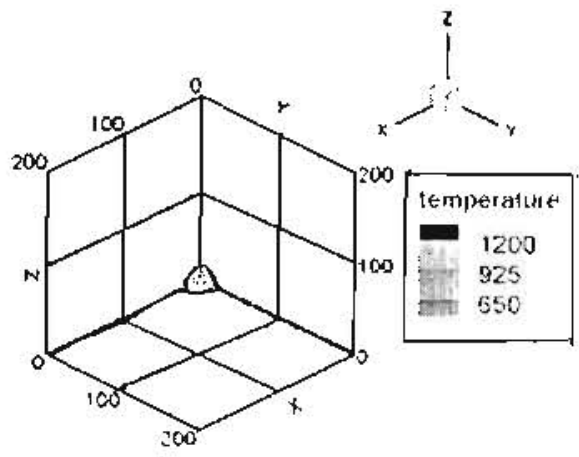

a. One day heated volume

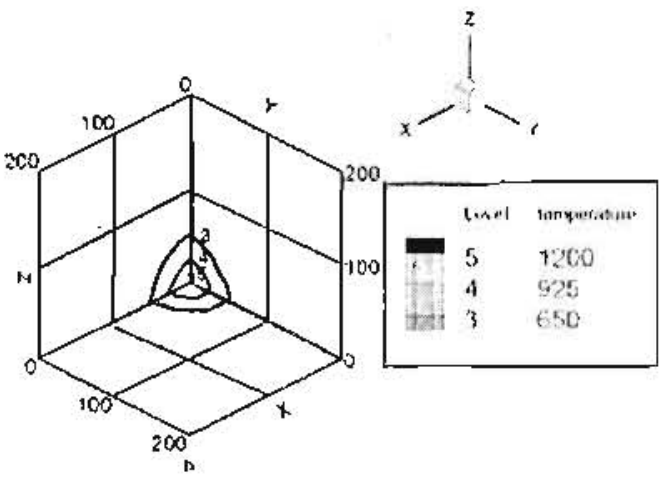

b. One week heated volume

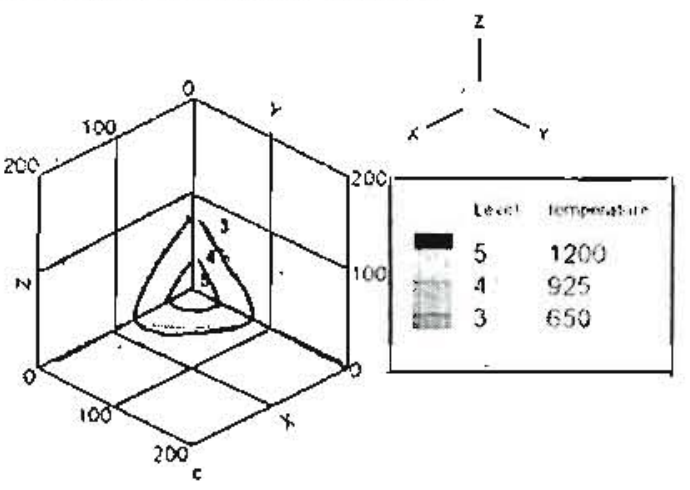

c. One month heated volume

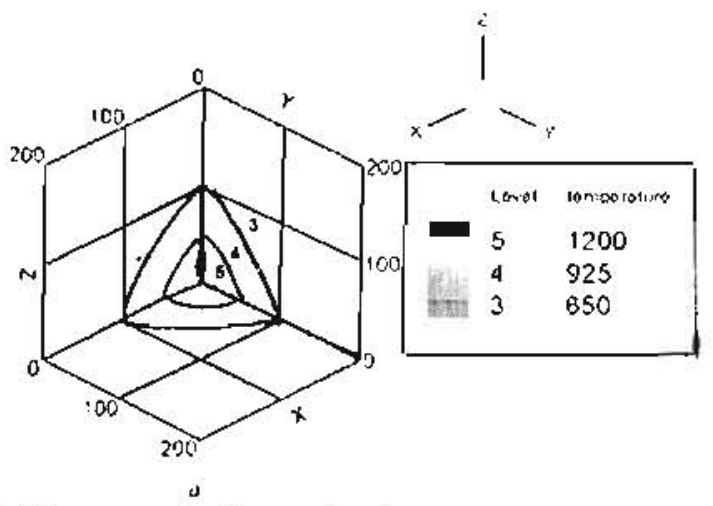

d. Two months heated volume

Fig.5 The heated volume and temperature contours variation with time for coal type $\mathrm{C}$ at heat source $1000^{\circ} \mathrm{C}$ 
Also the cases with the three coal types are solved theoretically for the heat source with 1500 and $2000^{\circ} \mathrm{C}$ where the variation of heated volume and one month period are represented in Fig.6 and Fig. 7 and temperature contours after one day

Type A

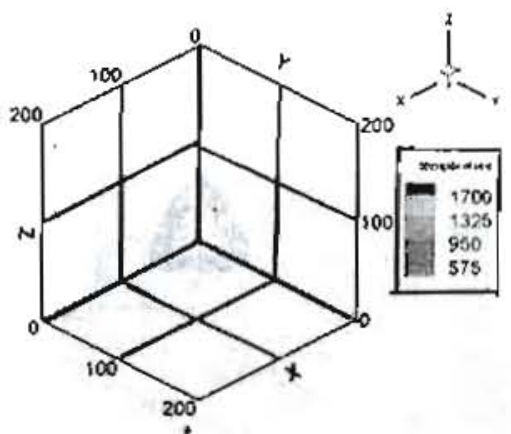

a. one day period

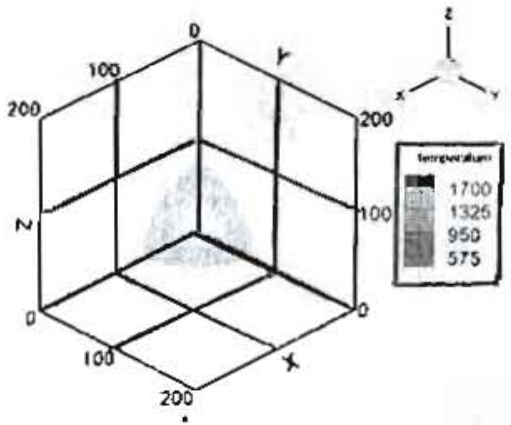

a. one day period

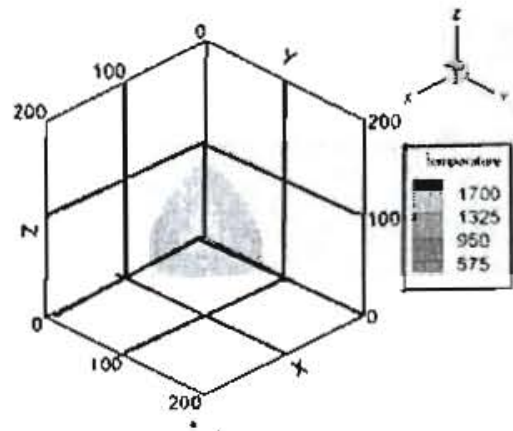

a. one day period respectively.

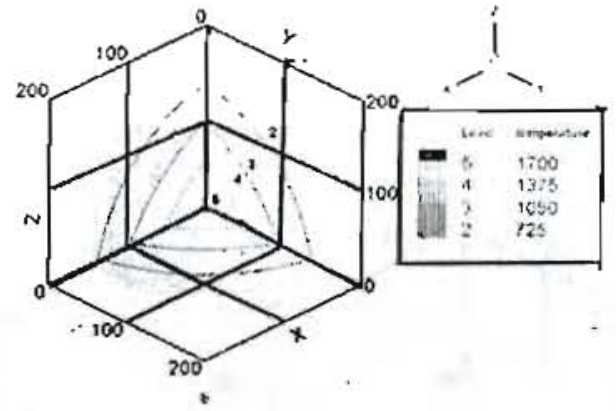

b. one month period

Type B

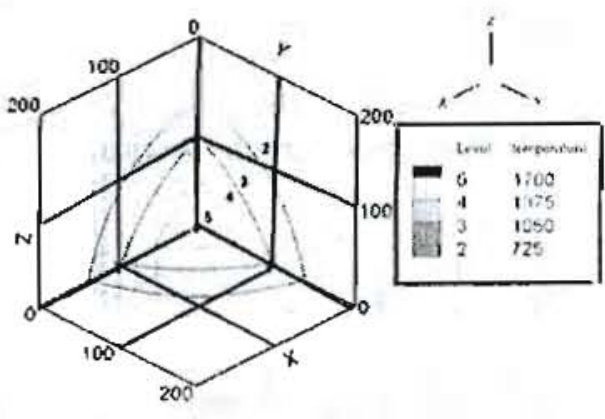

b. one month period

Type C

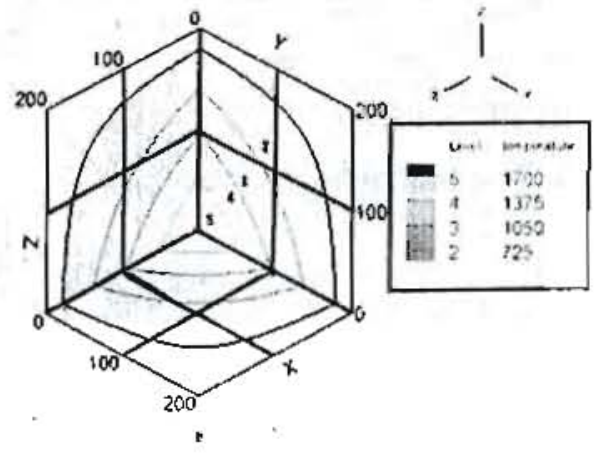

b. one month period

Flg.6. Comparison between the developed heated volume and temperature contours for the three types of coal after one day and one month period for heat source $1500^{\circ} \mathrm{C}$ 


\section{Type A}

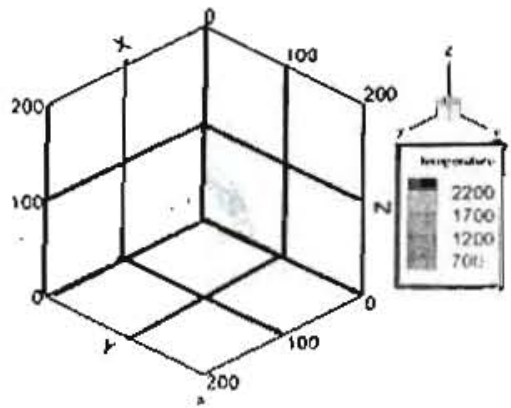

a. One day period

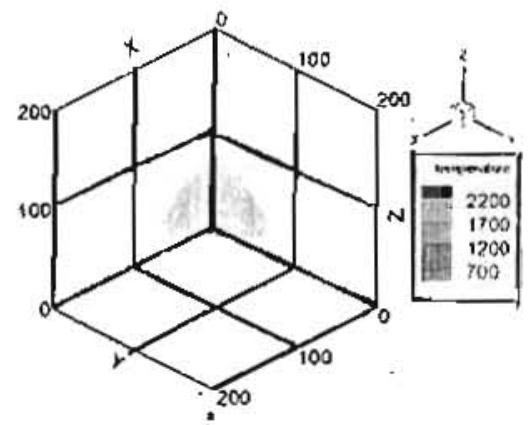

a. One day period

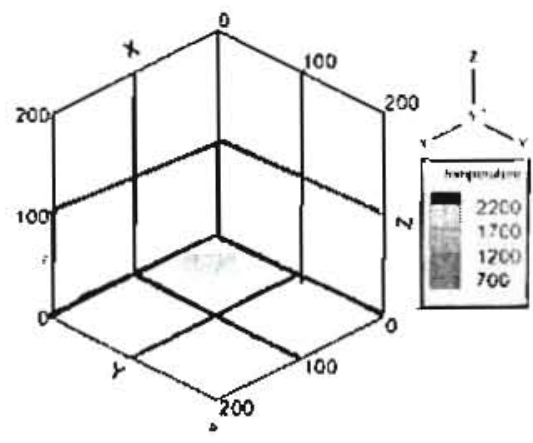

a. One day period

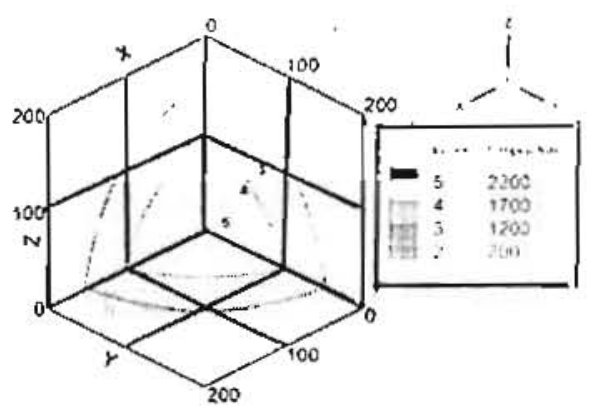

Type B a. One month period

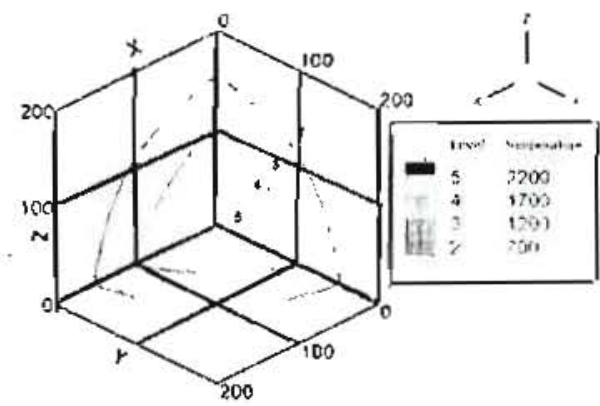

Type C

b. One month period

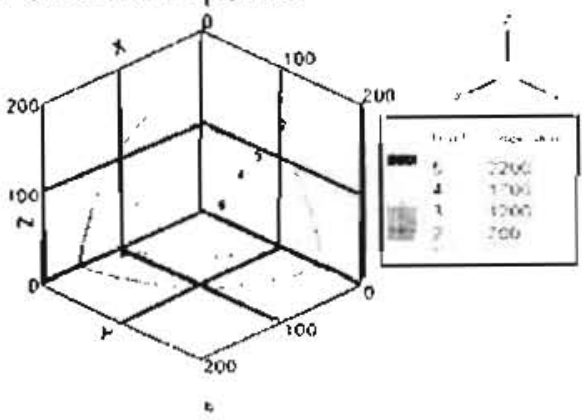

b. One month period

Fig.7. Comparison between the developed heated volume and temperature contours for the three types of coal after one day and one month period for heat source $2000^{\circ} \mathrm{C}$.

Analyzing the calculated results represented in Figs.3-7, it is concluded that the boundaries of heated volume increase with time and with heat source temperature. Also the heated volume of coal increases with thermal conductivity which depends on coal type. The heated volume increases rapidly at the beginning of trial and after certain period of time, the rate of its increase starts to decrease till reaching the steady state, at which its boundaries remains unchanged.

\subsubsection{Heat source inserted in the coal layer between two rock layers.}

Such model is solved as two dimensional problem as the width of coal layer is considered big enough 
and Eng. Ali Ahmed Ghali

compared with coal layer thickness and The theoretical solution of this case length. The heat source is inserted in the coal layer at different depth of rock in the range from $150 \mathrm{~m}$ to $500 \mathrm{~m}$, where the rock is granite with properties, density $\left(2750 \mathrm{~kg} / \mathrm{m}^{3}\right)$, specific heats $(0.89 \mathrm{KJ} / \mathrm{kg} . \mathrm{K})$, thermal conductivity $(2.9$ W/m.K) and thermal diffusivity $(0.012$ $\mathrm{cm}^{2} / \mathrm{s}$ ).

is applied for coal seam with different thickness range from $40 \mathrm{~m}$ to $400 \mathrm{~m}$ and different length range from $250 \mathrm{~m}$ to $1000 \mathrm{~m}$. The heated coal volumes and the temperature contours of two types of coal (type A \&C ) at heat source temperature $1750^{\circ} \mathrm{C}$ during different times of two weeks and one month are shown in Fig. 8

Type A

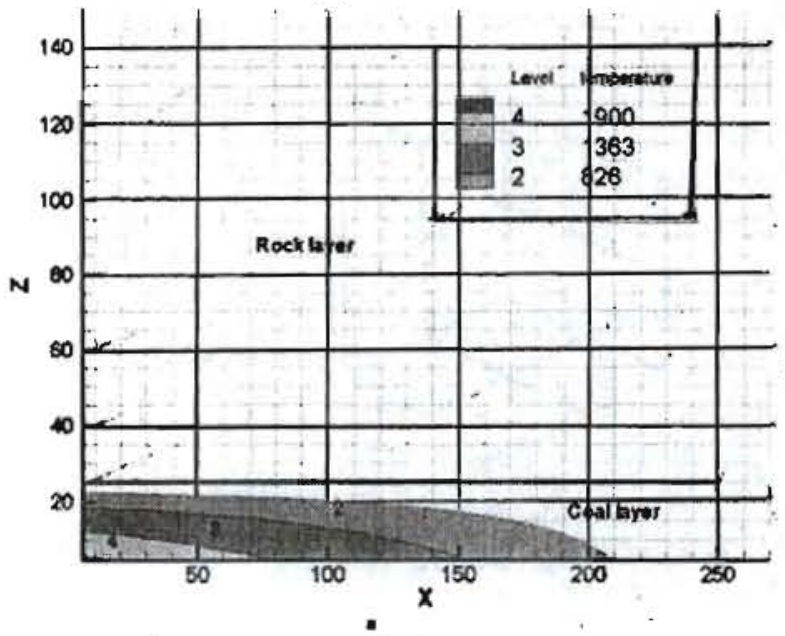

a. Two weeks period

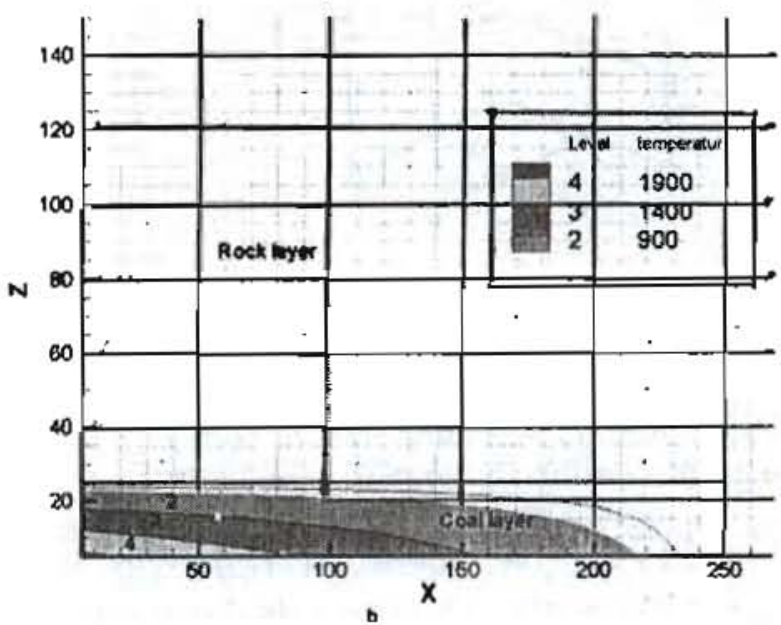

b. One month period

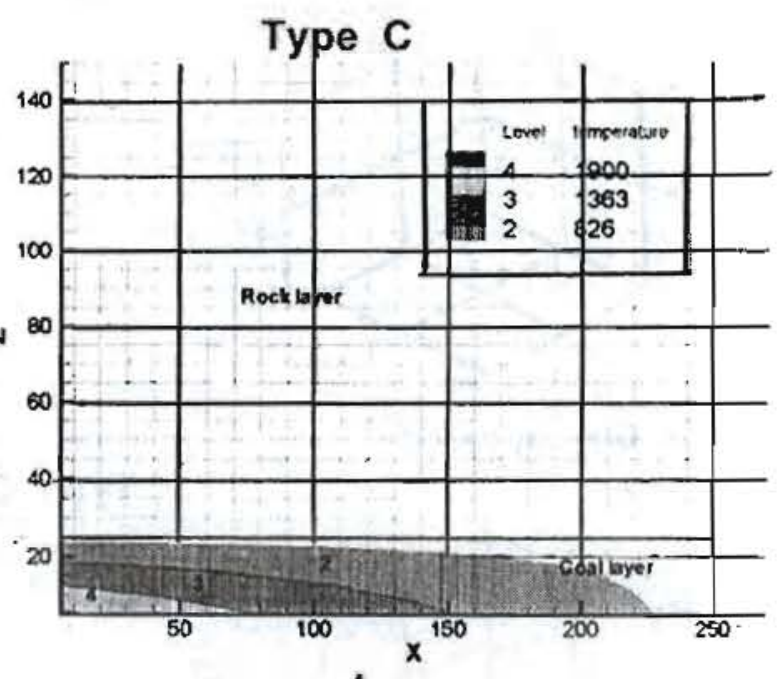

a. Two weeks period

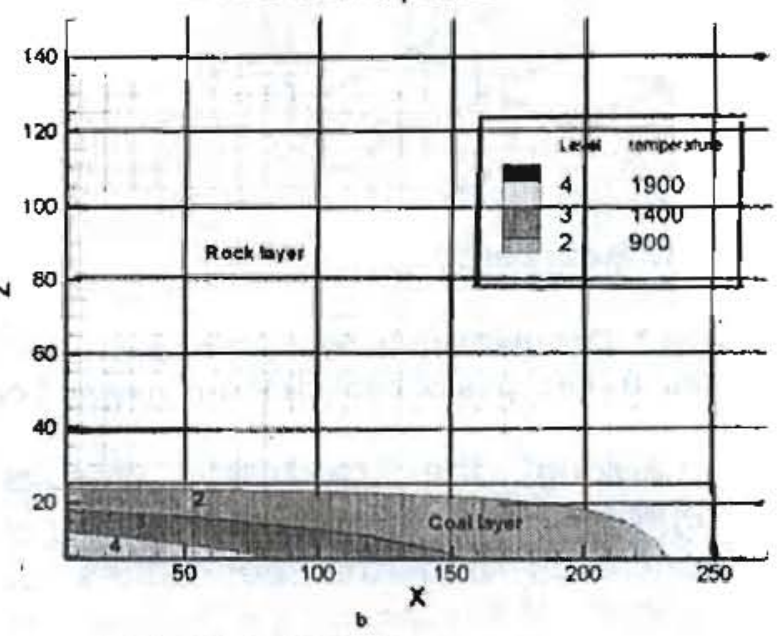

b. One month period

Fig. 8 The temperature contours variation ith time for coal type(A\&C), $40 \mathrm{~m}$ thickness at depth $150 \mathrm{~m}$ \& heat source $1750^{\circ} \mathrm{C}$

Also this model is solved considering coal type $C$ at the same heat source temperature but with depth $500 \mathrm{~m}$ and
Coal length $1000 \mathrm{~m}$, where the obtained results are shown in Fig.9. 


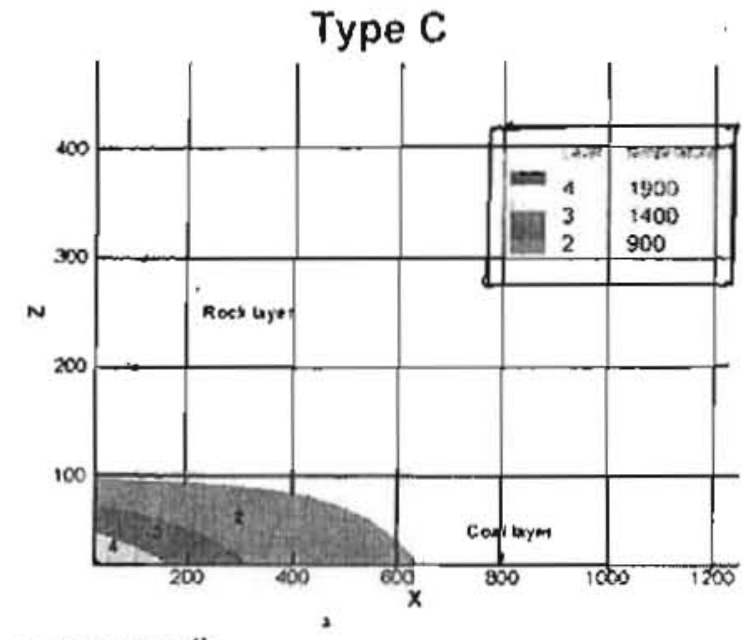

a. one month

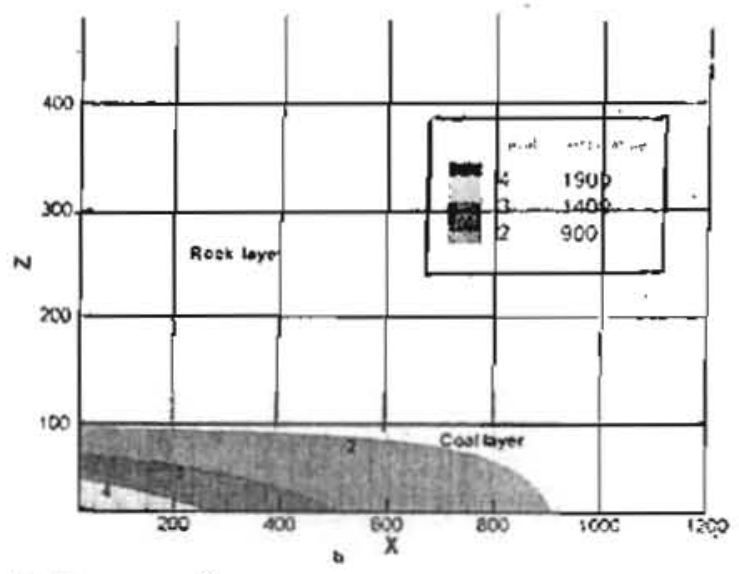

b. Two months

- Fig.9 The temperature contours variation with time for coal type C, 200m thickness at depth $500 \mathrm{~m} \&$ heat source $1750^{\circ} \mathrm{C}$.

To evaluate the obtained results let us define the heating velocity $\left(C_{h}\right)$ at any position as the rate of change of temperature with time, which given by the following relation:

$\mathrm{C}_{\mathrm{h}}=(\mathrm{dT} / \mathrm{dt})=\left(\mathrm{T}_{2}-\mathrm{T}_{1}\right) / \Delta \mathrm{t}_{(2-1)}$

where $T_{2}$ is the temperature at new. time $(t+\Delta t)$,

$T_{1}$ is initial temperature,

$\Delta \mathrm{t}_{(2-1)}$ is the time interval .

The heating velocity is a criterion by which the change of heated volume is evaluated, such that as $C_{h}$ approaches zero value, the steady state is reached. The obtained results show that the heating velocity in the coal layer increases in the beginning of trial with time and after a considered period the heating velocity decreases till reaching The steady state after two months approximately.

\subsubsection{The heat source inserted in rock layer}

Such model is also considered as 2-D problem where the effect of change of heat source temperature is studied in the range $1000^{\circ} \mathrm{C}$ to $2000^{\circ} \mathrm{C}$. The heat source is inserted in rock of Sandstone with: density $(2300 \mathrm{~kg} / \mathrm{m} 3)$, 'specific heat $(0.71 \mathrm{~kJ} / \mathrm{kg} . \mathrm{K})$, thermal conductivity $(2.1 \mathrm{~W} / \mathrm{m} . \mathrm{k})$ and thermal diffusivity $\left(0.013 \quad \mathrm{~cm}^{2} / \mathrm{s}\right)$. The considered model is $40 \mathrm{~m}$ thickness at $50 \mathrm{~m}$ depth, where the coal layer thickness is $20 \mathrm{~m}$ lies between two layers of rock each $10 \mathrm{~m}$ thickness. The obtained results is shown in Figs.10, $11 \& 12$. Figure 10 shows the variation of temperature contours for coal type $A$ with time for one day, one week, and one month, at heat source temperature of $1000^{\circ} \mathrm{C}$. While Figs. 11 \& 12 show the same variation at heat source temperature of $1500^{\circ} \mathrm{C}$ and $2000^{\circ} \mathrm{C}$ respectively. The obtained results show that the heated volume of gasified coal layer increase with time and with heat source temperatures where the steady states are reached after one month.

The percentage of gasified volume of coal is the amount of heated volume of coal which be able to gasify from total heated volume which a has temperature $\mathrm{T} \geq 400^{\circ} \mathrm{C}$. The percentage of gasified volume of different coal types ( $A \& B$ and $C$ ) with time at heat source $1000^{\circ} \mathrm{C}$, and $2000^{\circ} \mathrm{C}$ are represented as bar chart in Figs. 13 and14. 
M. 46 Aly M. El-Zahaby, M. Khalil Bassiouny, Ayman Bakry

and Eng. Ali Ahmed Ghali
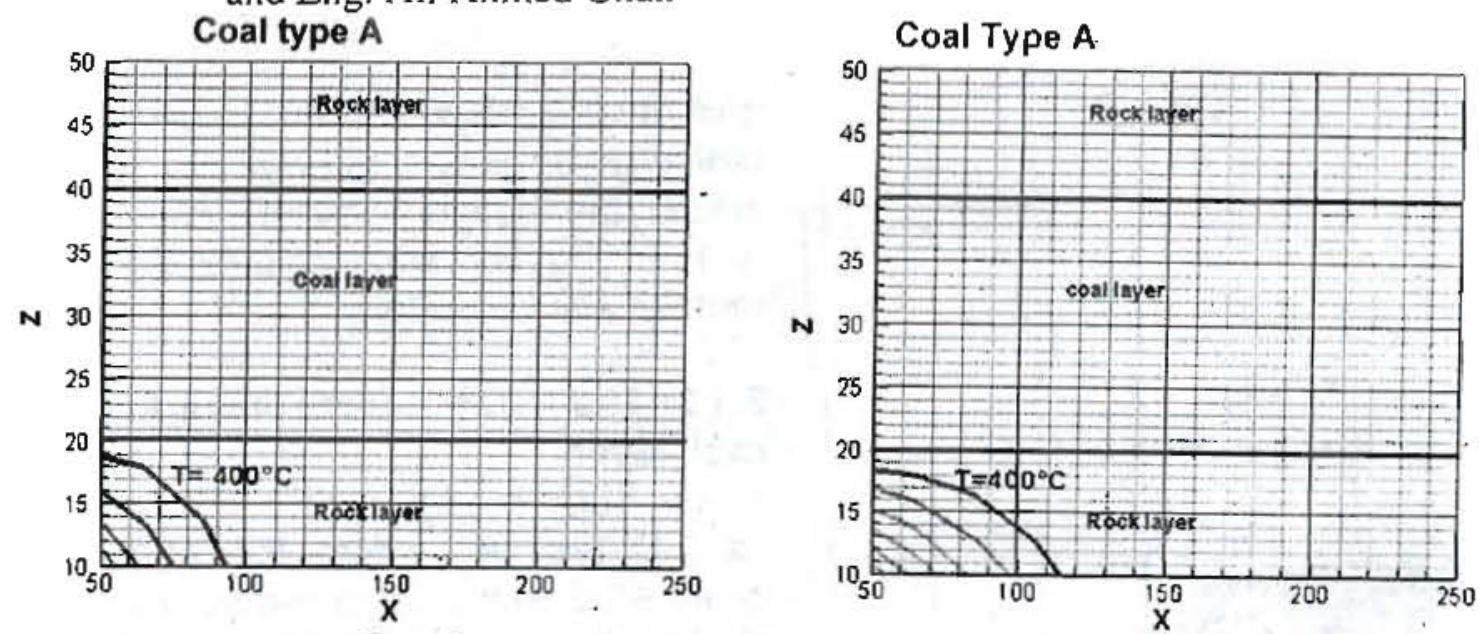

a. One day

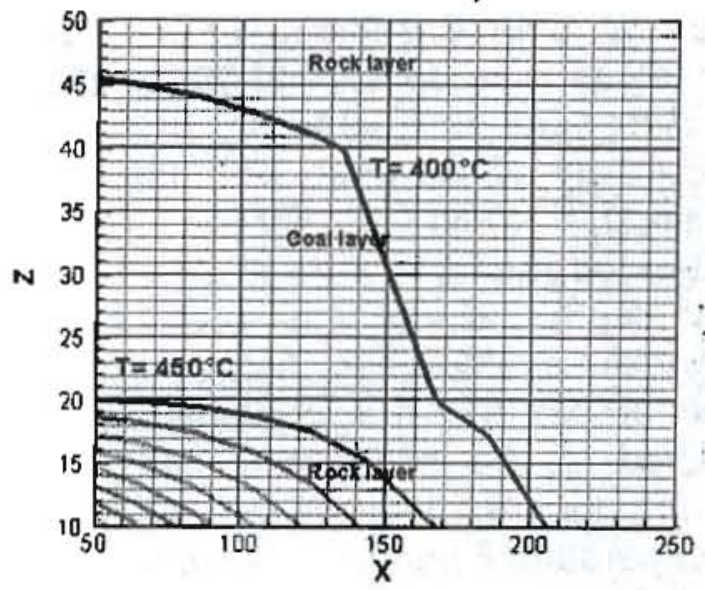

a. One week

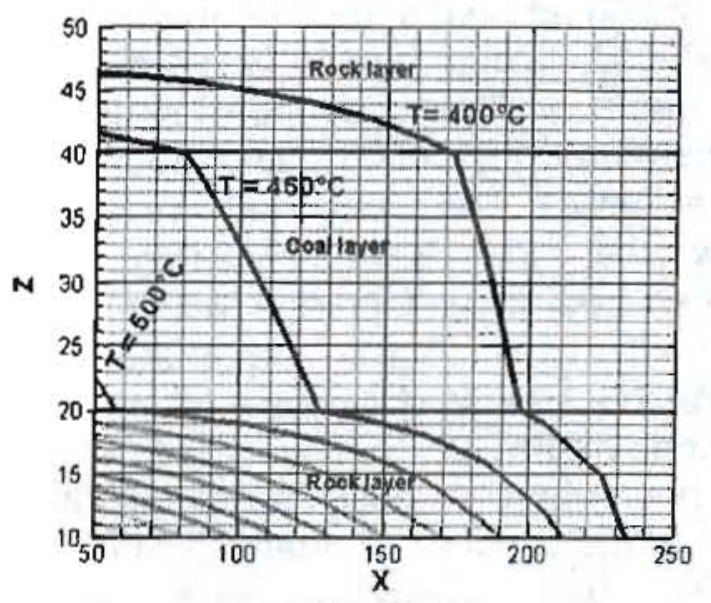

a. One month

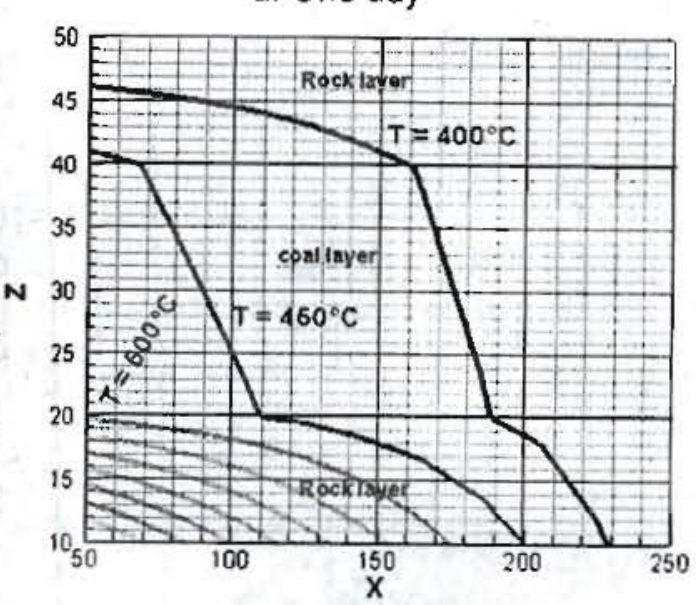

b. One week

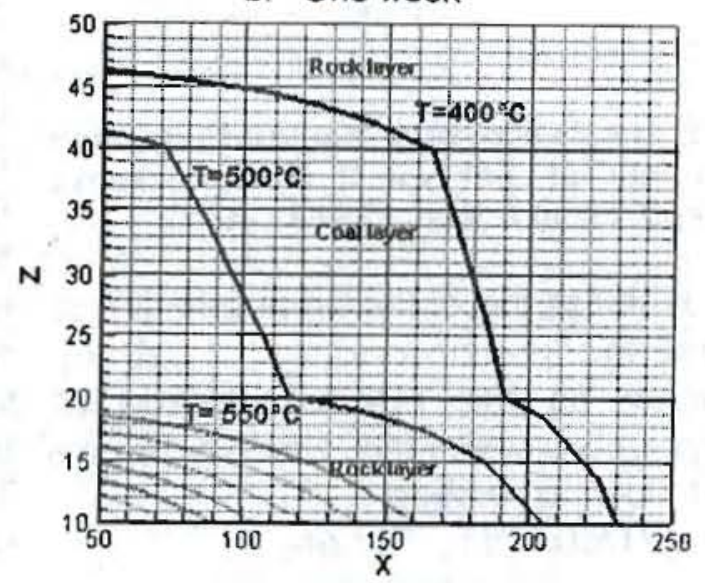

b. One month

Fig.10 Temperature profiles and heated volume of coal at different time periods for heat source with $1000^{\circ} \mathrm{C}$ inserted in rock layer $250 \mathrm{~m}$ length.

Fig.11. Temperature profiles and heated volume of coal at different times for heat source with heat source temperature $1500^{\circ} \mathrm{C}$ inserted in rock layer $250 \mathrm{~m}$ length. 
Coal Type A

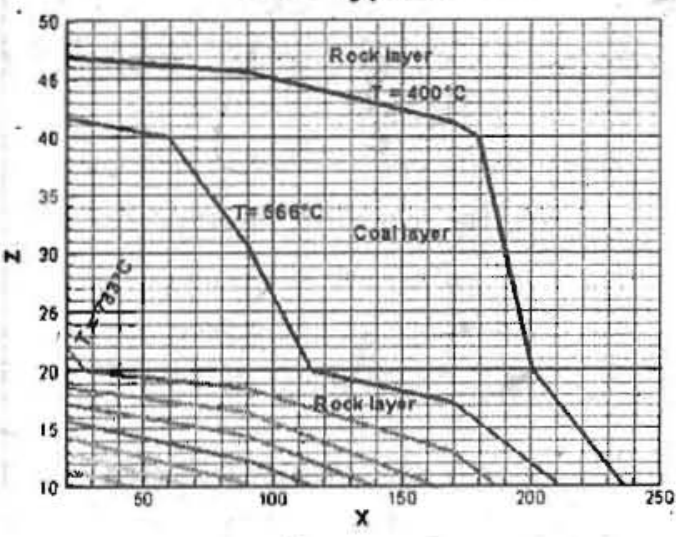

a. One week

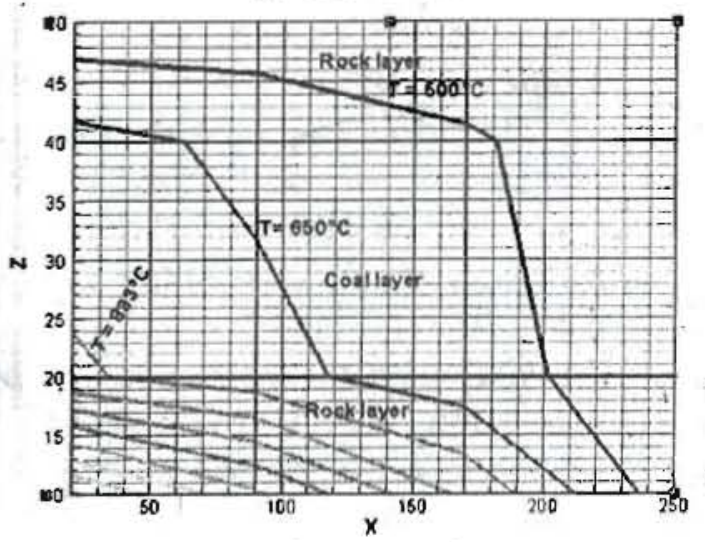

b. One month

Fig.12 Temperature proflles and heated volume of coal at different times, for heat source with temperature $2000^{\circ} \mathrm{C}$ inserted in rock layer $250 \mathrm{~m}$ length.

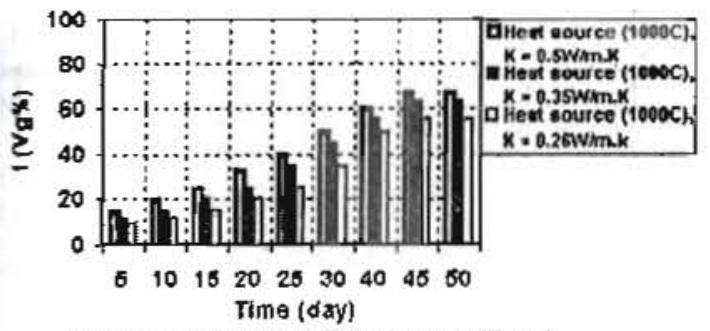

Fon.(1)!: grecentege of gastind volume of differem

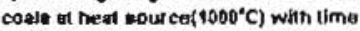

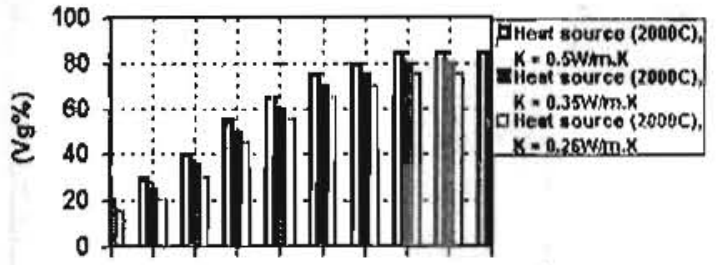

$\begin{array}{llllllll}6 & 10 & 16 & 20 & 25 & 39 & 40 & 60\end{array}$ TIme (day)

Fig.(14): Precerrege of gosined volumes of difterem cools at heat Bourre $\left(2000^{\circ} \mathrm{C}\right)$ wikh thrme

The results show that percentage of gasified volume of coal vary with time according to heating velocity in coal layers and the percentage of gasified volume of coal increases in the beginning of heating pyrolysis trial and reaches constant value at the end of trial depending on the heating velocity and type of coal. While the variation of heating velocity in coal seam with time for different coal types at heat source $1000^{\circ} \mathrm{C} \& 1500^{\circ} \mathrm{C}$ and $2000^{\circ} \mathrm{C}$ as bar chart are represented in Figs. $15 \& 16$ and 17. Theses figures indicate that the heating velocity increases with heat source temperature and decreases with time.

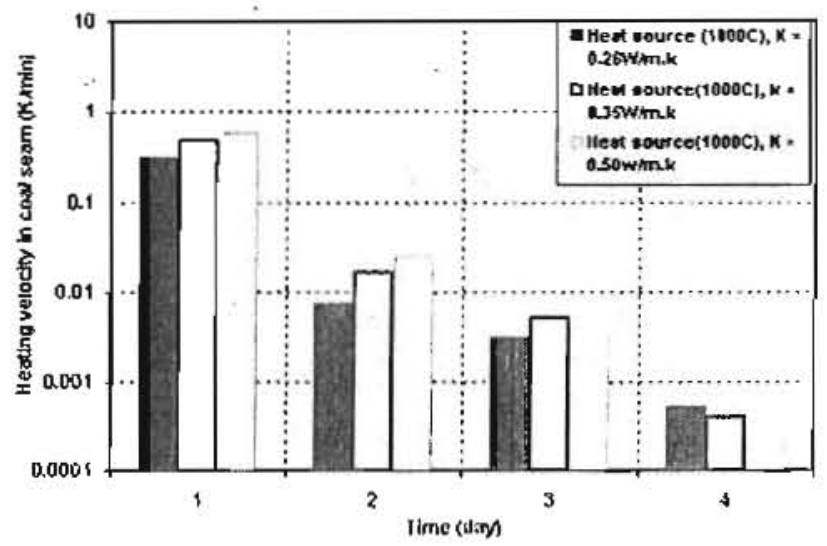

Fig. 16 Heating velocity in coal seam with time running and different types of coal at heat source $\left(1000^{\circ} \mathrm{C}\right)$

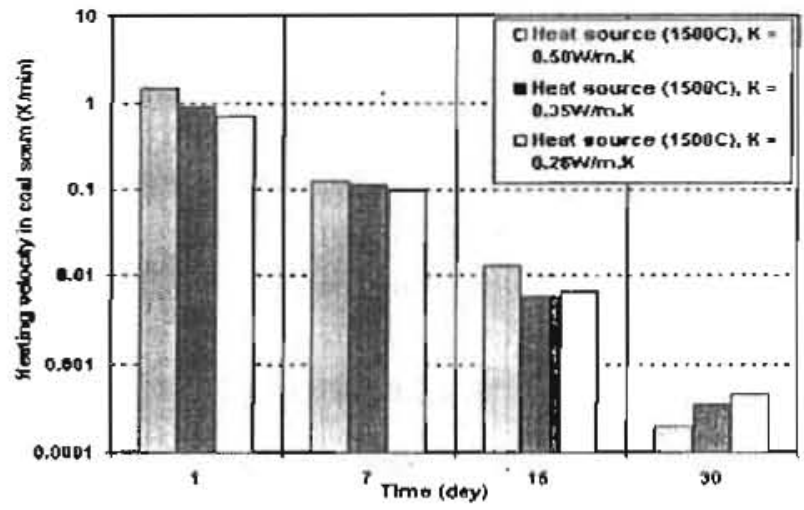

Fig. 16 Heallng velocity in coal seam with time running and different types of coal at heat soutce $\left(1500^{\circ} \mathrm{C}\right)$

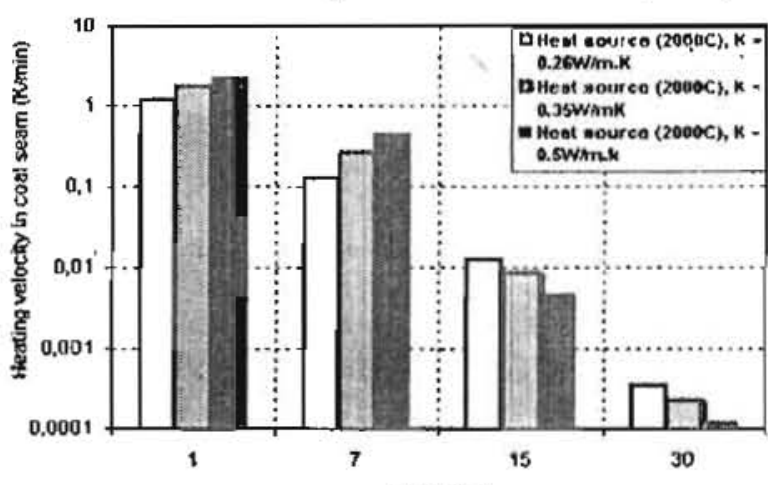

Fig. 17 Heallng velocity in coal soa m with tims runniny and difierent types of coal si hezi source $\left(2000^{\circ} \mathrm{C}\right.$ 
4. Efficiency of pyrolysis coal insitu

The efficiency of coal pyrolysis ( process is calculated for three cases a according to the heating method as follows :

1. Ideal case of homogeneous distribution of heating source.

2. Heating source inserted in

3 . Heating source inserted in rock.

Syngas composition results from pyrolysis of underground coal process varies based on many factors, including reactor type, feedstock, and processing conditions ( temperature, pressure, type reactant, etc.). The efficiency of coal pyrolysis

$(\eta)$ is defined as:

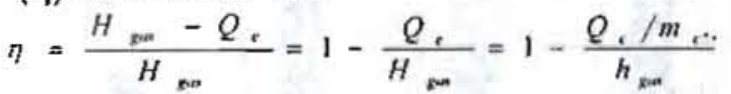

and

$$
h_{\mathrm{xas}}=\frac{H_{\mathrm{gus}}}{m_{\mathrm{c}}}
$$

Where $H_{\text {gas }}$ is the amount of heat content in gasses produced from pyrolysis coal (kJ) which given as:

$(\mathrm{kJ})$ which is given as:

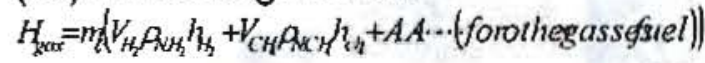

Where $m_{c}$ is mass of coal pyrolysis.

$V_{H_{2}}$ is the volume of hydrogen present in gas produced $\mathrm{m}^{3} / \mathrm{kg}$.

$V_{C: H}$ is the volume of methane present in gas produced $\mathrm{m}^{3} / \mathrm{kg}$.

$\rho_{N H_{1}}=\frac{M_{H_{1}}}{V_{N}}$

is the density of hydrogen at normal condition.

$\rho_{N i H_{1}}=\frac{M_{C H_{1}}}{V_{N}}$

is the density of methane at normal condition.

, $h_{\text {gas }}$ is the amount of heat content in gasses produced from pyrolysis coal per unit mass $(\mathrm{kJ} / \mathrm{kg})$, and $Q_{c}$ is the amount of heat used to heat the coal (kJ) which is given as:

$Q_{c}=m_{c} C_{p} \Delta T=m_{c} C_{p}\left(T_{h}-T_{i}\right)$

where $C_{p}$ is the specific heat of coal

$$
\text { (J/kg.K) }
$$

, $T_{b}$ is the temperature of heated coal

\subsection{Ideal case of homogeneous distribution of heating source.}

For this case table (3) shows the calculated efficiency for different coals at different temperature, where the amount of gases released and its composition at different temperature is taken from [8].Therefore results is represented in Fig.(18). The calculated efficiencies show that high efficiency at bituminous and lower efficiency at lignite are obtained .

Table 3: pyrolysis efficiency of different coals ( lignite, sub bituminous,

Bituminous) at different temperatures .

\begin{tabular}{|l|r|r|r|r|r|r|}
\hline \multicolumn{2}{|c|}{ Efficiency $\eta(\%)$} & & & & \\
\hline$T\left({ }^{\circ} \mathrm{C}\right)$ & 400 & 500 & 600 & 700 & 800 & 900 \\
\hline \begin{tabular}{l} 
Coal type \\
\hline Lignite
\end{tabular} & 89.1 & 80.1 & 74.53 & - & - & 59.59 \\
\hline $\begin{array}{l}\text { Sub- } \\
\text { bituminous } \\
\text { coal }\end{array}$ & 73.46 & 86.7 & 81.2 & 75.2 & 71.2 & 65.0 \\
\hline $\begin{array}{l}\text { Bituminous } \\
\text { coal }\end{array}$ & - & - & 91.0 & - & 86.27 & 88.7 \\
\hline
\end{tabular}

\subsection{Heating source inserted in infinite coal.}

Table (4) shows the pyrolysis efficiency of sub bituminous at different temperatures for heating source based on the amount of gases released and its composition [8]. 
Mansoura Engineering Journal, (MEJ), VoI. 33, No. 3, September 2008.

Table 4: pyrolysis efficiency of sub bituminous at different temperatures

\begin{tabular}{|c|c|c|c|c|c|c|}
\hline \multicolumn{7}{|c|}{ Efficiency $\eta(\%)$} \\
\hline $\mathrm{T}\left({ }^{\circ} \mathrm{C}\right)$ & 400 & 500 & 600. & 700 & 800 & 900 \\
\hline $\begin{array}{l}\text { Sub- } \\
\text { bituminous } \\
\text { coal }\end{array}$ & - & 65.38 & 78.62 & 80.4 & $\overline{77.3}$ & 73.1 \\
\hline
\end{tabular}

\subsection{Heating source inserted in rock}

The heat used for pyrolysis in-situ coal when heating source inserted in rock layer for heating surrounded coal is equal to the heat used for heating rock and the heat used for heating coal. The calculated pyrolysis efficiency of sub bituminous at different temperature for heat source inserted in rock is listed in table 5, based on the amount of gases released and its composition [8].

Table 5: the pyrolysis efflciency of in-situ coal when heating through inserting heat source in rock layer.

\begin{tabular}{|c|c|c|c|c|c|c|}
\hline \multicolumn{7}{|c|}{ Efficiency $7\langle \%\rangle$} \\
\hline $\mathrm{T}\left({ }^{\circ} \mathrm{C}\right)$ & 400 & 500 & 600 & 700 & 800 & 900 \\
\hline $\begin{array}{l}\text { Sub- } \\
\text { bituminous } \\
\text { coal }\end{array}$ & - & 34.5 & $\begin{array}{l}62.8 \\
3\end{array}$ & $\overline{68.1}$ & 64.9 & $\overline{60.1}$ \\
\hline
\end{tabular}

Figure (19) shows the relation between efficiency pyrolysis of in-situ coal at different temperature for different heat source positions. When heating source inserted in rock layer for heating coal, the maximum efficiency is $(68.1 \%)$ at $\left(700^{\circ} \mathrm{C}\right)$ and minimum efficiency is $(34.5 \%)$ at $\left(500^{\circ} \mathrm{C}\right)$. while for heating source inserted directly in coal, the maximum efficiency is $(80.4)$ at $\left(700^{\circ} \mathrm{C}\right)$ and minimum efficiency is $(65.39 \%)$ at temperature $\left(500^{\circ} \mathrm{C}\right)$.

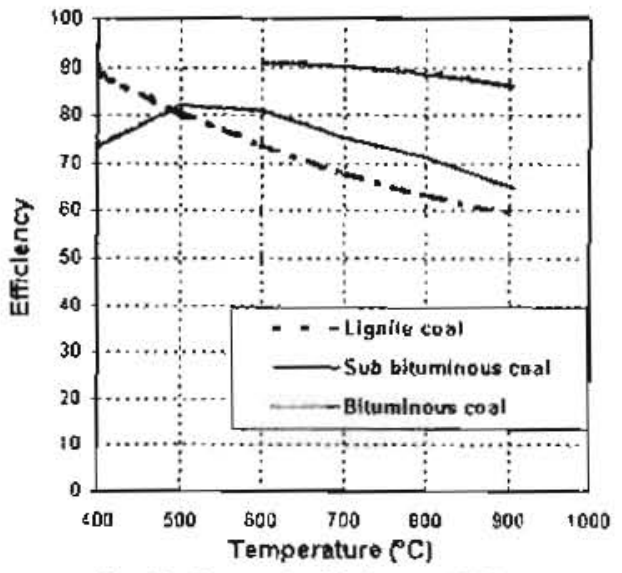

Flg. 18 Pyrolysis efficlency of different coals at different temperature

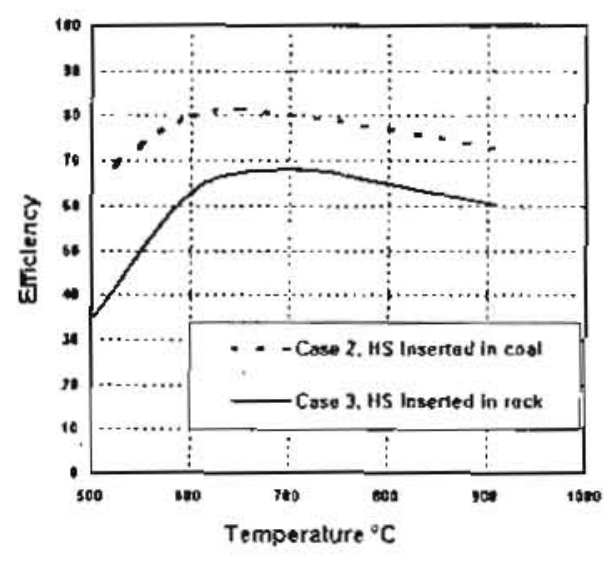

Flg 19 Pyrolysis efficlency of sub bituminous coal with different temperature for different positions

\section{Experimental Investigation}

The experimental set up simulates the considered theoretical model. The set-up as shown in fig. 20 consists of the following components: an insulated cubic iron tank $(1 \mathrm{~mm})$ thickness with dimensions $\left(0.5^{\star} 0.5^{\star} 0.5 \mathrm{~m}\right)$ filled with a pure coal of chemical composition $(85.5 \% \mathrm{c}$. $5 \% \mathrm{H} 2,7 \% 0,1 \% \mathrm{~S}, 1.5 \% \mathrm{~N})$, type $\mathrm{A}$, about $45 \mathrm{~cm}$ of coal height. Heating source is a heater of $3 \mathrm{~kW}$ power of radius $7.5 \mathrm{~cm}$. By using the temperature controller which have four channels, each channel can read and control one temperature. In the experiment the channel one is used for controlling the temperature of heat source installed at position $A$ in the center of cubic, and the other three channels are used for reading only the temperature of positions $B, C$, and 
and Eng. Ali Ahmed Ghali

D. The used temperature sensors are of type $J$, which positioned at concentric sphere a-round the heat source at radius $10 \mathrm{~cm}, 15 \mathrm{~cm}, 20 \mathrm{~cm}$ (position of $\mathrm{B}, \mathrm{C}$ and $\mathrm{D}$ ). The pyrolysis produce gases which is collected in a plastic vessel through pipes, valves. A sensitive balance is used to calculate the amount of gas produced and the Chromatography (Agilent 6890 Plus) device in Egyptian Petroleum Research Institute (EPRI) (not shown

in figure) is used for analyzing the produced gases. The heating source is a special electrical heater of (3kW) contained in an a spherical shape of iron with radius of $7.5 \mathrm{~cm}$. Using the temperature controller the center of cubic, from heating source temperature is selected $500^{\circ} \mathrm{C}, 800^{\circ} \mathrm{C}$ and $1000^{\circ} \mathrm{C}$. To avoid oxidation of pyrolysis gases and to enhance pyrolysis the space above the coal is evacuated using vacuum pump whereas its absolute pressure reaches 0.8 bar. For each selected temperature source all measured parameters: temperature, gas mass and time are continuously recorded.. Figure 21 shows the measured temperature variation with time at different position of coal seam(heat source $A$, and the other three position $B, C$ and D) together with theoretically estimated variation at heat source of $1000^{\circ} \mathrm{C}$ at the same positions. While

Fig. 22 shows the measured change of heating velocity in $0.45 \mathrm{~m}$ coal seam with time together with the theoretically calculated change for heat source temperature $1000^{\circ} \mathrm{C}$. Both figures show faire agreement between the measured and calculated results due to the differences properties of the considered physical coal in theoretical and experimental studies. The gas results from pyrolysis process during the time of experimental is the amount of produced gas due pyrolysis at heat source of $1000^{\circ} \mathrm{C}$. Also three samples of the produced gas is taken using special traps. These samples are analyzed in Egyptian Petroleum Research Institute (EPRI) using the Gas Chromatography (Agilent 6890 Plus)device. The gas analysis gives: $24.48 \% \mathrm{CH}_{4}, 6.8 \% \mathrm{C}_{2} \mathrm{H}_{6}, 8.3 \% \mathrm{C}_{3} \mathrm{H}_{8}$, $13 \% \quad \mathrm{C}_{4} \mathrm{H} 10,11.6 \% \quad \mathrm{C}_{5} \mathrm{H}_{12}, \quad 5.6 \%$ $\mathrm{C}_{6} \mathrm{H}_{14}, 4.5 \% \quad \mathrm{C}_{7} \mathrm{H}_{16}, 7.6 \% \mathrm{C}_{8} \mathrm{H}_{18}$ and other hydrocarbons, etc. The results show that $\mathrm{CH}_{4}$ is essentially a main product of pyrolysis, and this results agree with the results of (A. Williams, M. Pourkashanian, J. M. Jones and N. Skorupska. "Combustion and gasification of coal").[3] The gasification using pyrolysis in this trial starts as the temperature of heated coal layer reaches $400^{\circ} \mathrm{C}$, where the released gases flow through pipes are collected in plastic vessel. The mass of the plastic vessel containing released gases are continuously recorded together with time. The gasification rate is calculated using the relation:

$$
(\mathrm{m} 2-\mathrm{m} 1) /(\mathrm{t} 2-\mathrm{t} 1) \text {. }
$$

The experiment is repeated several time, and the gasification rate takes the value $(0.078$ to 0.082$) \mathrm{gm} / \mathrm{min}$. After considerable time (6h), the heating velocity decreases to about zero value, at which the steady state conditions is reached. 


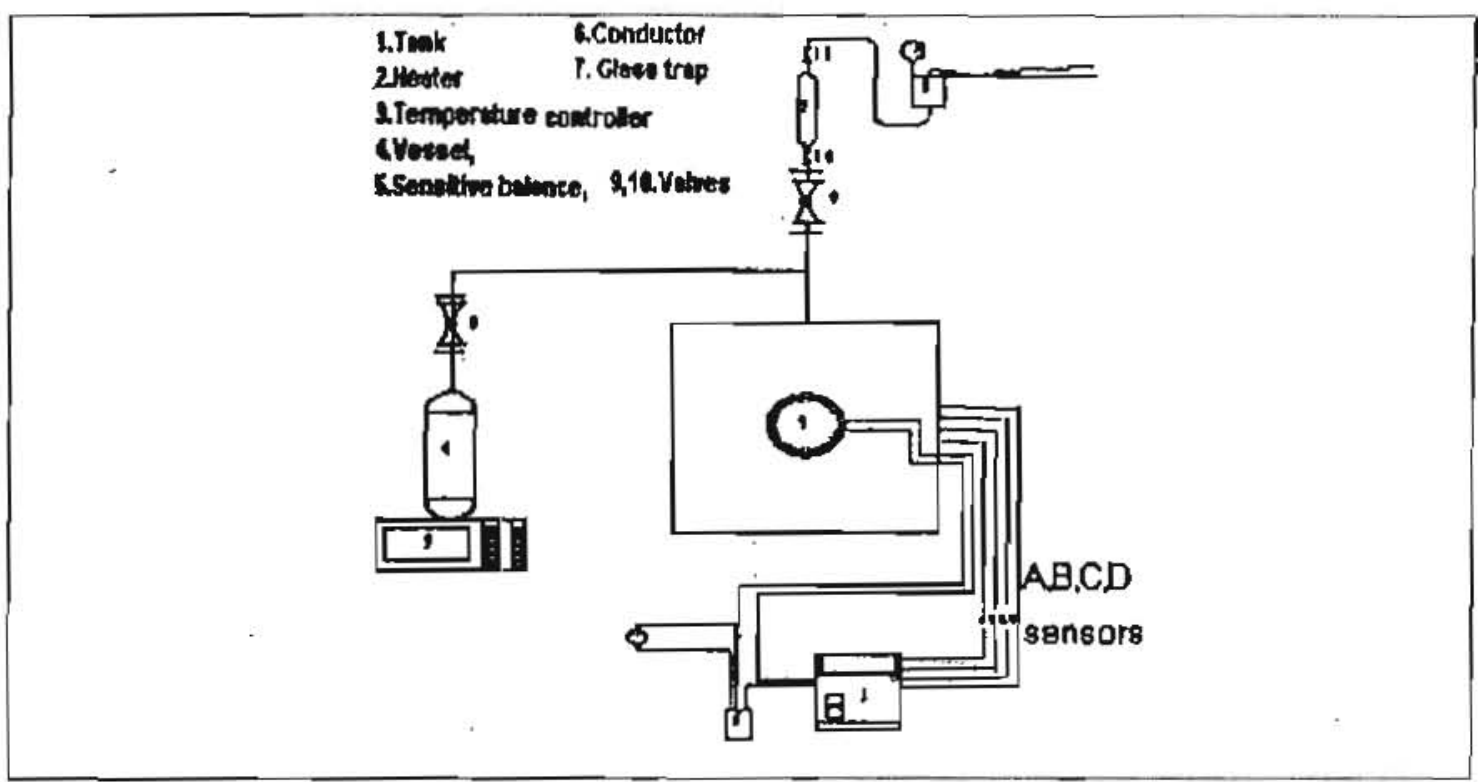

Figure (20): Scheme of the experimental set up.

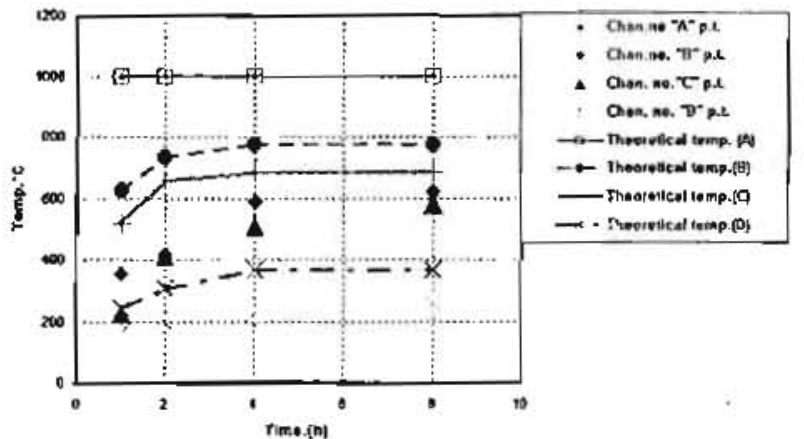

Fle. 25 Temperzture distribution in 0.5m cosil seam with time at hazl source $1000^{\circ} \mathrm{C}$, data from prograriming and expefimental sel up

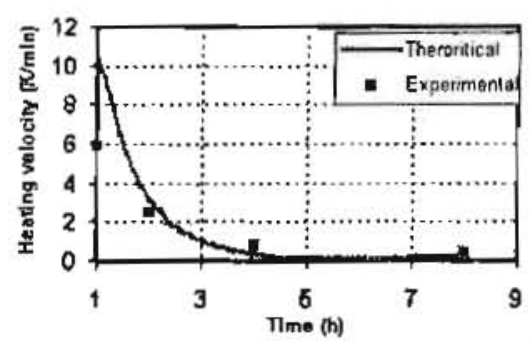

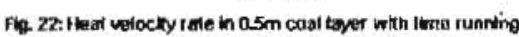
data from therolkcol prooramentigand exeptimental sol up

\section{Conclusion}

The considered theoretical and experimental study of pyrolysis process indicate that:

1.the pyrolysis of underground coal required a complete design and economic analysis of a considerable parameter such as depth, thickness, types and nature of geology. So the important technical requirements and consideration should be taken in designing a commercial gas production from underground coal gasification in-situ by pyrolysis pyrolysis proicess such as:a surface temperature of heating source, location and spacing (distance) between the heating sources, heating velocity, production rate of gases, its composition and thermal efficiency, in addition to the developing technology including geological variables,

2. The formulated mathematical model for analyzing the unsteadystate heat conduction during an insitu pyrolysis of underground coal in order to release gas gives a fair agreement with the experimental results and therefore it can be used for the design and economic analysis of definite pyrolysis process.

3.The temperature distribution in the coal seams depends on the temperature of the heating source, the time running, and the geometry. The heating velocity in coal seams have the mean value between (2 to $10^{-3} \mathrm{~K} / \mathrm{min}$.) which increases quickly in the beginning of trial, after a considered time it 
M. 52 Aly M. El-Zahaby, M. Khatil Bassiouny, Ayman Bakry

and Eng. Ali Ahmed Ghali

decreases and approaches zero at steady state conditions.

4.The operating temperatures of pyrolysis is about $400^{\circ} \mathrm{C}$, then thermal decomposition occurs and organic materials are transformed into gases with composition analysis as $\left(\mathrm{CH}_{4}\right.$, $\mathrm{C}_{2} \mathrm{H}_{6}, \mathrm{C}_{2} \mathrm{H}_{4}, \mathrm{C}_{2} \mathrm{H}_{2}, \mathrm{C}_{3} \mathrm{H}_{8}, \mathrm{H}_{2}, \mathrm{CO}_{2}$ ).

5. The efficiency of in-situ coal pyrolysis depends on the coal

compositions where the best temperatures are between $\left(700-800^{\circ} \mathrm{C}\right)$ at which the high efficiency of pyrolysis process occurs and high amount of gas produced with high calorific value of heat.

6. This study might be useful in constructing an in situ pyrolysis project for under ground coal.

\section{Reference}

1. Saghafi and Venna Sahajwalla university of New South Wales, Sdney Australia" Numerical modelling of underground coal gasification and its application to Australian coal seam conditions", 2004.

2. Patanker.S.V. Numerical heat transfer and fluid flow, (1979).

3. Leeds, UK. A. Williams, $M$. Pourkashanian, and J. M. Jones.Swindon,UK, N.Skorupska," Combustion and gasification of coal " (2000).

4. Patanker. S. V) A Numerical method for conduction in Composite Materials, Flow in irregular Geometrices and Conjugate Heat Transfer, Proc.6th Int. Heat TransferConf. Tronto., (1978)

5. Adrain Bejan "heat transfer". John Wiley \& Sons, Inc.New York Chichester, (1990).

6. Michael Serio, James Markham, Marek Wojtowicz Advanced Fuel Research, Inc.Energy Consulting Services Functional-Group, Depolymerization, Vaporization, Cross-iinking Model The FG-DVC Model Description and Validation, (2004).
7. M. Kaltschmitt and AV Bridgwater in Biomass Gasification and Pyrolysis of Coal. .(2000).

8. John Rezaiyan, Nicholas Technologies ", published P Cheremisinoff "Gasification in by CRC Press Tayior\& Francis Group.(2005).

9. Ronald F. Probstein, Professor of Mechanical Engineering Massachuseees Institute of Technology and Water Purification Associates, R. Edwin Hicks, Water Purification Associates "Synthetic Fuels", McGraw-Hili International book company, 662.66, (2002).

10. United States, Environmental and Protection Agency EPA/816-R-99014m September "The Class V Underground Injection Control InSitu Fossil Fuel Recovery WellS",(1999)

11..Oakey, Power Generation Technology Centre, Cranfield University ,C L. Shah, School of Chemical, Environmental and Mining Engineering, University of Nottingham and Li Wenhua, China Coal Research Institute, Beijing, "China worshop on CHINA-UK research collaboration on cleaner coal technologies" Report No. Coal R194 DTI/Pub URN 00/967,2001".

12.. Karin Dutton Advanced Fuel Research, Inc.Copyright (c) 19972005 Advanced Fuel Research.

13. FRTR, Remediation Techriologies Screening Matrix and Reference Guide, version $4.0,4.24$ pyrolysis Copyright @ 2005 Geotec, Inc. \& Richcorp, Inc

14. Klass,D.L.,Biomass for renewable Energy, fuel, and chemicals. Academic press, 1998 